\title{
The Heterogeneous Impact of High-Speed Railway on Urban Expansion in China
}

\author{
Dan $\mathrm{He}^{1}{ }^{1}$, Zixuan Chen ${ }^{1}$, Jing Zhou ${ }^{2, *} \mathbb{C}$, Ting Yang ${ }^{1}$ and Linlin $\mathrm{Lu}^{3}{ }^{\mathbb{C}}$ \\ 1 College of Applied Arts and Science, Beijing Union University, Beijing 100191, China; \\ hedan@buu.edu.cn (D.H.); $191070510101 @ b u u . e d u . c n(Z . C.) ; 20201070510112 @ b u u . e d u . c n$ (T.Y.) \\ 2 State Key Laboratory of Tibetan Plateau Earth System, Resources and Environment, \\ Institute of Tibetan Plateau Research, Chinese Academy of Sciences, Beijing 100101, China \\ 3 Key Laboratory of Digital Earth Science, Aerospace Information Research Institute, \\ Chinese Academy of Sciences, Beijing 100094, China; lull@radi.ac.cn \\ * Correspondence: zhoujing@itpcas.ac.cn; Tel.: +86-137-1811-8976
}

Citation: He, D.; Chen, Z.; Zhou, J.; Yang, T.; Lu, L. The Heterogeneous Impact of High-Speed Railway on Urban Expansion in China. Remote Sens. 2021, 13, 4914. https://doi.org/ $10.3390 /$ rs13234914

Academic Editors: Belen Riveiro and Mario Soilán

Received: 23 October 2021

Accepted: 29 November 2021

Published: 3 December 2021

Publisher's Note: MDPI stays neutral with regard to jurisdictional claims in published maps and institutional affiliations.

Copyright: (c) 2021 by the authors. Licensee MDPI, Basel, Switzerland. This article is an open access article distributed under the terms and conditions of the Creative Commons Attribution (CC BY) license (https:/ / creativecommons.org/licenses/by/ $4.0 /)$.

\begin{abstract}
High-speed railway (HSR) promote the efficient flow of the population and materials between cities and have profoundly affected urban economic development in China. However, there is currently limited research about how HSR influences urban expansion, especially related to the variable impacts on different urban agglomerations, different size cities, and the conversion of non-urban land to urban land. In this study, from two levels of regional heterogeneity and type heterogeneity, a multi-stage difference-in-differences (multi-stage DID) model and land use remote sensing data are used to investigate these research areas. The main conclusions are as follows: (1) The first opening of HSR had a more significant role in promoting urban expansion than HSR frequency, but several years after opening, HSR no longer promotes urban expansion. (2) The opening of HSR only played a significant role in promoting urban expansion in Beijing-Tianjin-Hebei. HSR frequency had a significant role in promoting urban expansion in the Yangtze River Delta. (3) The opening of HSR had no significant impact on urban expansion for different size cities, and HSR frequency only had a significant negative impact on urban expansion of small cities. (4) The first opening of HSR led to urban expansion dominated by the occupation of cultivated land. Cities in Xinjiang and Inner Mongolia mainly converted barren land and vegetation cover to urban land after the first opening of HSR. In northeast China, the first opening of HSR made the conversion of vegetation cover and cultivated land to urban land roughly equivalent in size. The results of this study are helpful to understand the impact of the first opening of HSR and the scale of conversion of different types of non-urban land into urban land on urban expansion. In the era of HSR, these findings provide a valuable reference for regional planning and preventing the disorderly expansion of cities.
\end{abstract}

Keywords: HSR; urban expansion; heterogeneity; multi-stage DID model; land use; China

\section{Introduction}

High-speed railway (HSR) refers to the trains that operate at a speed of not less than $200 \mathrm{~km}$ per hour. Since 2008, China has entered an era of large-scale construction, with the opening and expansion of HSR. At present, China's HSR lines have the longest mileage in the world [1]. Due to the advantages of extremely high speed, comfortable riding environment, and precise control of train running time, HSR has greatly compressed spacetime distance and improved the efficiency and frequency of population flow between cities. These developments have provided unprecedented opportunities for industrial development and the expansion of cities where the HSR lines pass. The construction and operation of HSR has had a profound impact on the economy, tourism, land use, urban landscape, inter-city flow patterns, and urban hierarchy [2-9]. For instance, in Germany, HSR has reduced the commuting time between cities, causing employees to return from large cities to small cities to find jobs [10]. The function of HSR lines affects how 
tourists choose their travel destinations, which in turn affects the development of tourism in different regions along the line [11]. Beckerich et al. [12] found that HSR stations in different locations have a significant impact on the site selection of different types of firms. The impact of HSR on land use has gradually received attention. Martin et al. [13] confirmed that the opening of Spain's HSR improved accessibility and reduced the connectivity of the land use landscape. In cities of different levels, the intensity of the land use change in the HSR station area has a certain degree of heterogeneity [14].

China's urbanization process and the intensity of urban expansion have achieved rapid rise since the 1990s. China has experienced a stage of rapid urbanization, with urban land and permanent population increasing. Thanks to the rapid progress of urbanization, China has now entered a new stage of rapid economic and high-quality development. An important indicator of urbanization is the area growth of urban land. According to the China Urban Construction Statistical Yearbook [15], as of 2019, the area of urban built-up area has reached $60,312.45 \mathrm{~km}^{2}$, and the area of urban construction land has reached $58,307.71 \mathrm{~km}^{2}$. In 1990 , the above indicators were $12,855.7 \mathrm{~km}^{2}$ and $11,608.3 \mathrm{~km}^{2}$, respectively. In nearly 30 years, urban land has increased by four times. Not only China, but many countries all over the world are experiencing rapid urbanization. Therefore, the expansion of urban land has attracted a lot of attention. A large number of studies have analyzed the temporal and spatial evolution features and causes of urban expansion [16-19]. Socio-economic variables, accessibility, and geographic conditions are considered as important factors affecting urban expansion [20-26]. The relationship between HSR development and the spatial changes of urban land has attracted widespread attention. The emergence of HSR potentially promotes urban expansion to meet the needs of rapid industrial development and accelerates urbanization. Since 2008, the urban expansion of a large number of cities in China that have opened HSR has undergone major changes compared to before the opening of HSR. Therefore, studying the impact of HSR on urban expansion is critical, so as to provide information for regional land use planning, the development of HSR in new cities, and urban land management.

At present, there are disagreements on the positive and negative effects of HSR on urban expansion. Some scholars argue that HSR actively promotes the outward expansion of cities [27-31]. However, other scholars believe that HSR will limit urban expansion [32,33]. For example, Long et al. [29] proposed that the opening of HSR has a positive impact on accelerating urban expansion. This impact generally lags behind by five years and has a heterogeneous effect on different cities. Wang et al. [34] used reverse gravity and gravity deviation models to show that the introduction of HSR networks in cities without HSR had a greater impact on urban land growth than cities with HSR. In addition, the center of gravity of urban land shifted to the HSR station. Wenner et al. [35] found that the location of HSR stations has a significant impact on the evolution of land use, and an example is that HSR stations on the fringe of cities in Europe have stronger urban land expansion. Based on empirical tests of panel data from 65 cities of different sizes in China, Wang et al. [33] found that in a sample of cities with high accessibility, the rapid development of HSR had a significant inhibitory effect on urban sprawl. Furthermore, HSR promoted intensive development of urban land and restrained the low-density and disorderly expansion of cities. For example, Wang et al. [36] suggested that the siphoning and diffusion effects brought by HSR have an impact on urban contraction and expansion, according to the example of Northeast China. HSR may weaken the traffic accessibility and urban scale, then decrease, and finally they can lead to urban atrophy.

Some scholars have explored the influencing mechanism of HSR on urban expansion and have drawn conclusions from empirical models. For example, Tan et al. [31] explored the impacts of the opening of HSR stations, the number of HSR stations, and the number of HSR lines on urban expansion. This study suggested that the impact of HSR construction on urban land use conversion shows regional heterogeneity and depends on the city's economy, industry, and population scale. Zhu et al. [37] developed a DPSIR-PLS (driving forces, pressures, state, impact, responses-partial least squares) model and explored the impact of 
HSR on urban land use. This study concluded that the industrial agglomeration effect of HSR and incentives from local governments were the causal mechanism for the correlation between HSR and urban expansion. Deng et al. [38] analyzed the influence of HSR on urban sprawl depending on variable city size characteristics, location characteristics, and the location of HSR stations. This study proposed that the tertiary industry agglomeration, population agglomeration, income effects, and urban development demand caused by HSR worsen urban sprawl. Based on the spatial distribution and temporal accessibility of HSR, Wang et al. [39] suggested that HSR construction can improve accessibility, produce a time-space convergence effect, and promote reconfiguration of production factors, which cause the agglomeration of population and industry. These changes would speed up the expansion of urban land and the reorganization of urban spatial structures. Shen et al. [28] also found that HSR station (Atocha station) improved accessibility, which in turn promoted the growth of the population and employment opportunities and thus caused urban expansion. Garmendia et al. [40] found that HSR stations have helped cities along the Spanish HSR lines attract immigrants and family investment in the province and provide an impetus for urban residential development and urban growth. Based on empirical results, Zhu et al. [41] found that HSR have accelerated the efficiency of inter-city logistics, attracted industrial agglomeration, and generated industrial clusters, which provided an impetus for urban expansion. The increased accessibility of cities in the HSR network significantly promoted the expansion of urban land near HSR stations, and this was more prominent in large cities [42].

Although previous research has analyzed the spatial-temporal impact of HSR, urban expansion will inevitably be accompanied by the encroachment of non-urban land. At present, the analysis and cognition of the influence of HSR on the transformation of land use, especially the conversion of non-urban land to urban land, lack depth of research. China pays attention to the protection of the ecological environment, and urban expansion will inevitably lead to a loss of these ecosystems. Monitoring the conversion of urban land in cities with opened HSR can help prevent the excessive occupation of ecological land or farmland. These can help prevent the disorderly expansion of cities and improve urban planning. The key questions of this research are: How does HSR affect urban expansion in China? What are the differences in the impact of HSR on different urban agglomerations and different size cities? How does HSR impact the conversion of non-urban land to urban land?

For research methods, research on HSR, urban expansion, and land use usually uses a DID (difference-in-difference) or multi-stage DID model [41-43]. Multiple linear regression (MLR) [38], the spatial mixed logit (SML) model [28] and the spatial differencein-difference (SDID) model [3] also have certain applications. Compared with the MLR model, DID, multi-stage DID, and SDID models can identify differences in socio-economic performance before and after policy implementation, that is, they analyze the impact of policy implementation on socio-economic factors [44-46]. The opening of HSR can be regarded as a policy. One of the objectives of this research is to study the impact of the opening of HSR on urban expansion. Therefore, the DID model is suitable for this research. However, DID and SDID cannot solve the problem of the random opening of HSR in a certain period the same way as multi-stage DID [5], that is, the policy implementation is not in the same year, so this study selects the multi-stage DID model. However, this model also has its limitations, that is, it does not consider the spatial autocorrelation of dependent variables the same way as the SDID model [3].

The purpose of this paper is to use the multi-stage DID model and land use remote sensing data, select the opening of HSR, HSR frequency, and other socio-economic variables to study the impact of China's HSR on urban expansion from 2010 to 2019. In addition, through the calculation of land use conversion area and proportion, the impact of the first opening of HSR on the conversion of non-urban land to urban land is detected. The contribution of this article is to probe the heterogeneous impact of China's HSR on urban expansion from two aspects: regional heterogeneity and type heterogeneity. In terms of regional heterogeneity, starting from multiple spatial scales, the impact of HSR on the urban 
expansion of overall China, five typical urban agglomerations, and cities of different sizes is analyzed separately. In terms of type heterogeneity, the impact of HSR on the conversion of different types of non-urban land into urban land is analyzed. This research has greatly enriched the spatial research on the linkage between HSR and urban expansion from multiple levels and multiple scales and is conducive to the prediction of the conversion of different types of land of cities and the protection of non-urban land in the era of HSR.

\section{Materials and Methods}

\subsection{Study Area and HSR Network in China}

The study area was 230 prefecture-level cities that have opened HSR as of 2019, including many huge cities such as Beijing, Guangzhou, Shanghai, and Shenzhen. Due to factors such as topography and population distribution, there are more cities in Western China that have not yet opened HSR, so the number in the sample is relatively small. In 2019 , the total urban land area of the study area was $122,846.037 \mathrm{~km}^{2}$, the GDP totaled $87,786,249$ million yuan, and the urban population totaled 331.7591 million [15,47].

Since 2008, China has had its first high-speed railway, which is the Beijing-Tianjin Intercity Railway. China's HSR network (except Taiwan) as of 2019 is shown in Figure 1. China's HSR has achieved full coverage in 31 provinces except Tibet (the capital is Lhasa) and Macao. The HSR in the eastern region started earlier and has formed multiple corridors such as Beijing-Guangzhou, Beijing-Shanghai, Shanghai-Wuhan, and Shanghai-Changsha. Since 2014, there has been a gradual increase in HSR lines in the western region, but at present it is still mainly for communication with eastern cities, and the HSR lines between western cities are relatively weak. In Figure 1, if the opening time of each HSR line is 2018-2019, this means the opening time is from January 2018 to December 2019, and the rest can be deduced by analogy.

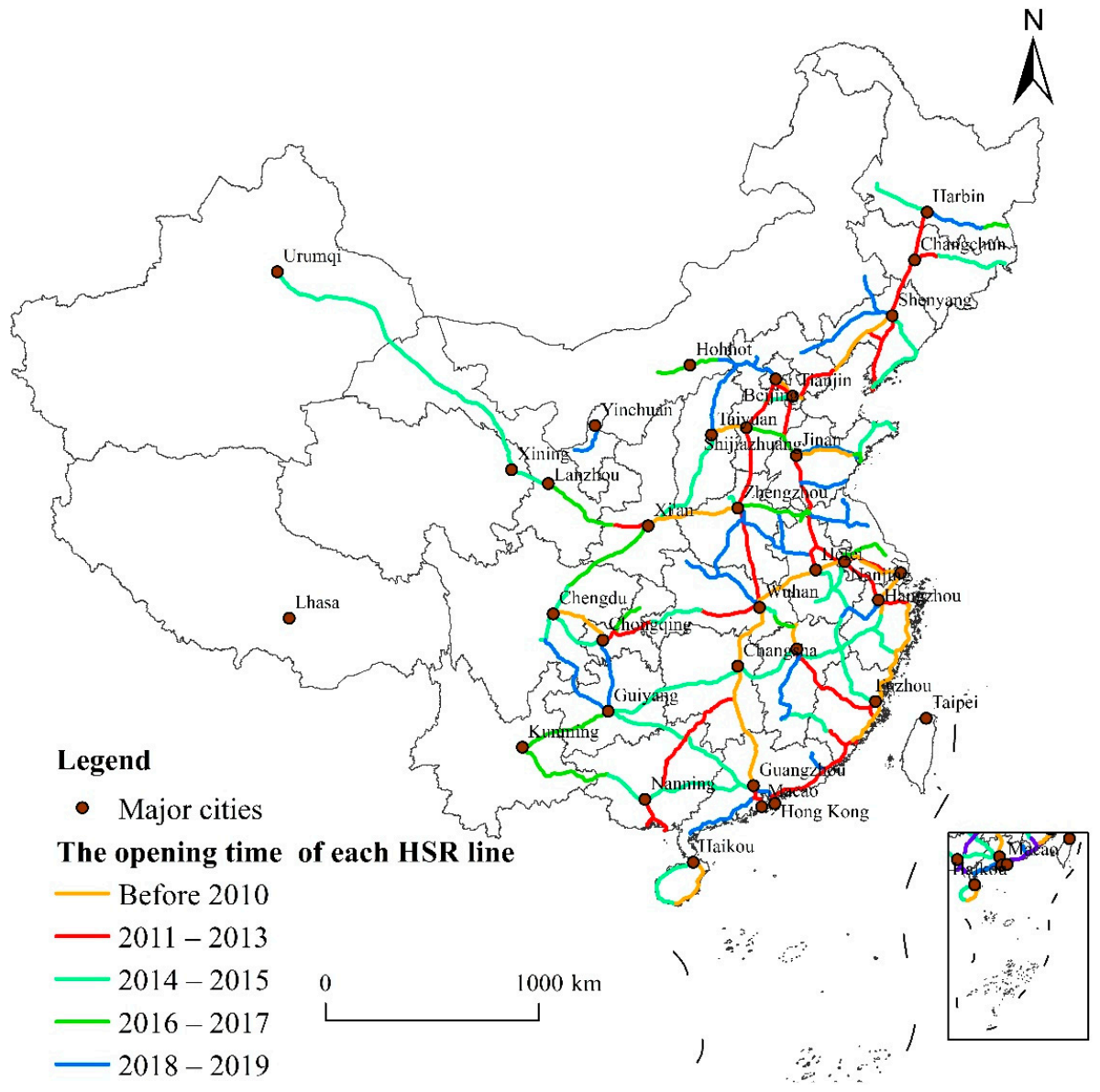

Figure 1. HSR network in China (2019). 


\subsection{Multi-Stage Difference-in-Differences (Multi-Stage DID) Model}

A DID model is an empirical method for estimating causal effects. The model evaluates the implementation of public policies as a natural experiment [44-46]. This study uses the opening of HSR as a policy in this model to study the impact of it on urban expansion [48]. The emergence of HSR has greatly increased the flow of population, material, capital, and other factors, bringing development opportunities for cities, which can stimulate urban expansion and rapid development. The model requires two differences. The first difference is to divide all variables into a treatment group and a control group. The former represents the group affected by the policy (i.e., cities that have opened HSR) and the latter represents the group that is not affected by the policy (i.e., cities that have not yet opened HSR). According to the difference before and after the opening of HSR, the changes in the urban land of the two groups are obtained. The first difference can eliminate the heterogeneity of individual cities that do not change over time. The second difference identifies changes of the two groups to eliminate increases over time and quantify the net effect of the opening of HSR [43]. The opening time of HSR in each city are randomly distributed between 2010 and 2019 rather than concentrated in one year. Therefore, the traditional DID model needs to be slightly changed, and this study finally uses a multi-stage DID model, as shown in Equation (1) [5,49].

$$
\ln \left(\text { urbanarea }_{\mathrm{it}}\right)=\beta_{0}+\beta_{1} \text { openingHSR }_{\mathrm{it}}+\gamma \sum_{\mathrm{n}} \text { Controls }_{\mathrm{it}}+\mu_{\mathrm{i}}+\mathrm{f}_{\mathrm{t}}+\varepsilon_{\mathrm{it}}
$$

where urbanarea ${ }_{i t}$ represents the urban land area of the city $i$ in year $t$ and uses logarithmic processing to calculate $\ln \left(\right.$ urbanarea $_{\text {it }}$ ) and make the dependent variable normally distributed. The dummy variable openingHSR ${ }_{i t}$ indicates whether a city i opened HSR in year $t$; if HSR opened, the value is 1 and if not, it is $0 . \sum_{n} C_{\text {Controls }}$ it indicates the economic and social control variables (Table 1), $n=7 . \gamma$ is the regression coefficient of the control variables. $\mu_{\mathrm{i}}$ is the individual fixed effect (that is, one city means an individual. We use "City" to represent this). $f_{t}$ is the time fixed effect (that is, time means 2010 . . 2019. We use "Year" to represent this), which is the time corresponding to all variables of each sample. $\beta_{0}$ is a constant term. $\beta_{1}$ represents the regression coefficient of the dummy variable. If $\beta_{1}$ is positive and significant, then the opening of HSR brings the growth in urban expansion. If $\beta_{1}$ is negative and significant, then the opening of HSR brings the reduction in urban expansion. If $\beta_{1}$ is non-significant, then the opening of HSR does not exert a significant effect on urban expansion. $\varepsilon_{\text {it }}$ represents a random error term. Each multi-stage DID model in this paper is processed with Stata16.0 software. It is worth mentioning that the number of samples put into the model is from a total of 10 years from 2010 to 2019, so the number of observations is 2300 (230 cities (which have opened HSR as of 2019) * 10 years).

Table 1. The introduction and description of all variables.

\begin{tabular}{|c|c|c|}
\hline Variables Type & Name & Code \\
\hline Dependent variable & urban land area & $\ln ($ urbanarea) \\
\hline Dummy variable & whether to open HSR & openingHSR \\
\hline Control variables & $\begin{array}{c}\text { regional GDP } \\
\text { per capita GDP } \\
\text { the proportion of secondary industry added value in GDP } \\
\text { the proportion of tertiary industry added value in GDP } \\
\text { the total retail sales of consumer goods } \\
\text { the total profits of industrial enterprises above designated size } \\
\text { HSR frequency }\end{array}$ & $\begin{array}{c}\text { GDP } \\
\text { perGDP } \\
\text { added value of the secondary industry } \\
\text { added value of the tertiary industry } \\
\text { retail } \\
\text { industry } \\
\text { HSR frequency }\end{array}$ \\
\hline
\end{tabular}

According to previous research [3,29,38,41-43], we selected regional GDP, per capita GDP, the proportion of secondary industry added value in GDP, the proportion of tertiary industry added value in GDP, the total retail sales of consumer goods, the total profits of 
industrial enterprises above designated size, and HSR frequency as the control variables. All variables are shown in Table 1.

\subsection{Data Sources}

Urban land data from 2010 to 2019 were sourced from the European Space Agency's global land use remote sensing dataset [50]. The spatial resolution of this data is $300 \mathrm{~m}$, and it uses the WGS84 geographic coordinate system. We use the vector map of the whole territory of China to obtain the land use distribution map over the years through mask extraction. For the data classification, please see the literature [51]. A variety of vegetation categories (including tree cover, grassland, shrubland, etc.) were merged into a vegetation cover layer, and the original water body, permanent ice, and snow were merged into a water body layer. Finally, these data were reclassified into five categories: urban land, water body, barren land, vegetation cover, and cultivated land. Urban land can be directly extracted from attribute 190. HSR frequency data were sourced from the Shengming, Jipin, and Zhinanzhen timetable software [52-54]. The statistics on social and economic aspects came from China City Statistical Yearbook from 2011 to 2020 [47].

The distribution of various types of land use in 2019 are shown in Figure 2, and this process was conducted with ArcGIS 10.5.1 software. Urban land is mainly distributed in the east of China, and there is little urban land in the west due to topographical conditions. The area of urban land is still small after many years of urbanization. The area of vegetation cover is the most extensive. The area of cultivated land ranks second and mainly distributes in the flat areas of the central and eastern regions, while the barren land is concentrated in the northwest of China.

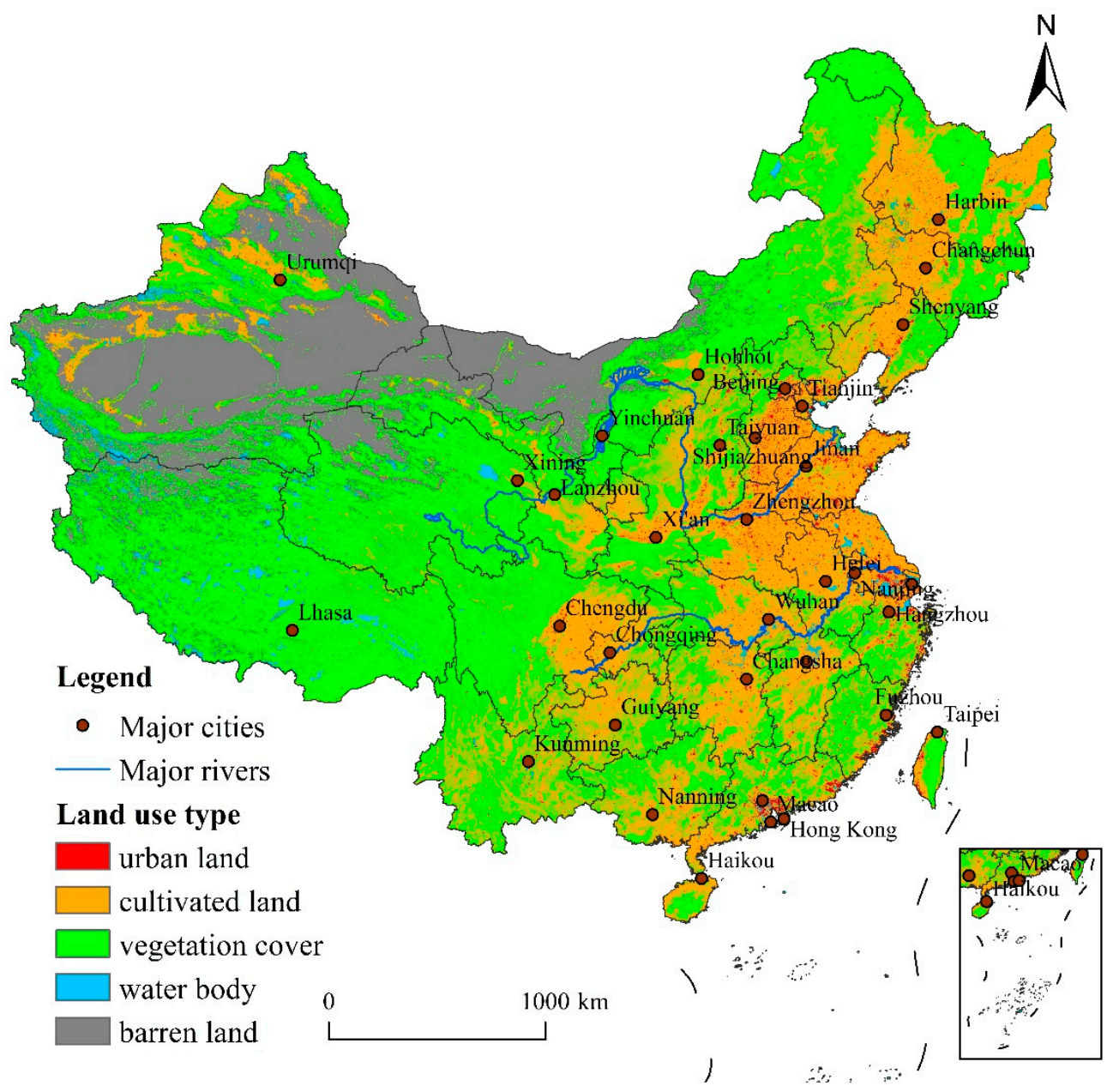

Figure 2. The distribution of land use in China (2019). 


\section{Results}

\subsection{Changes of Urban Land Area in China}

Urban land area data from 2010 to 2019 were extracted and mapped (Figure 3), and this process was conducted with ArcGIS 10.5.1 software (ESRI, California, America). It is not easy to intuitively obtain the changing trends of urban land areas, so the statistics of urban land areas were analyzed later.

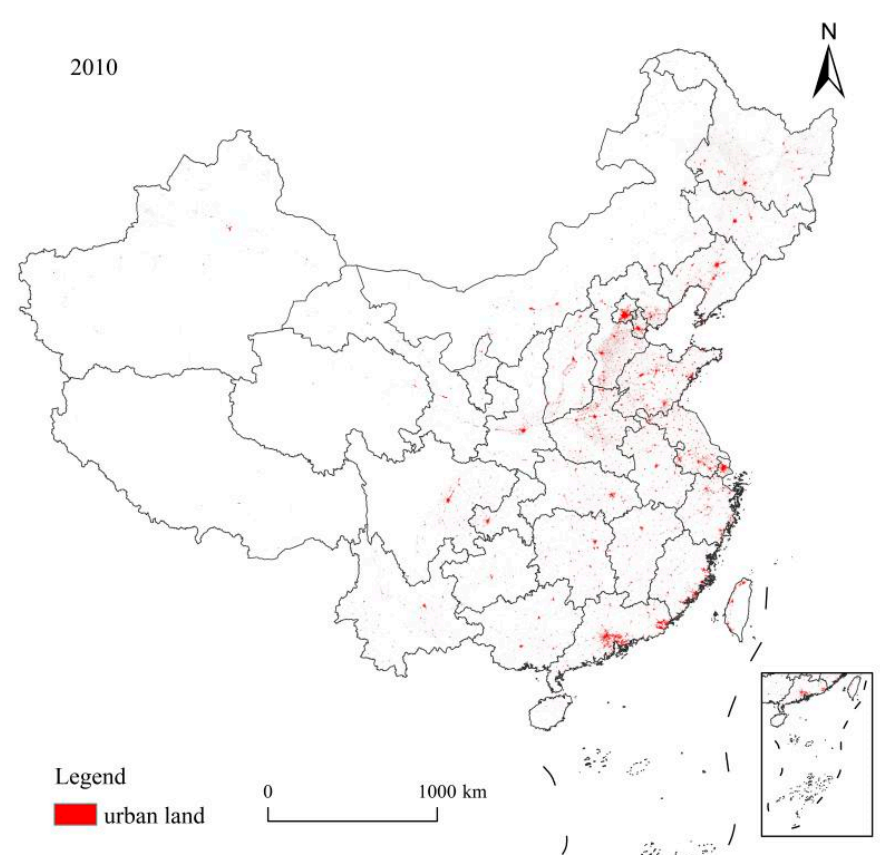

(a)

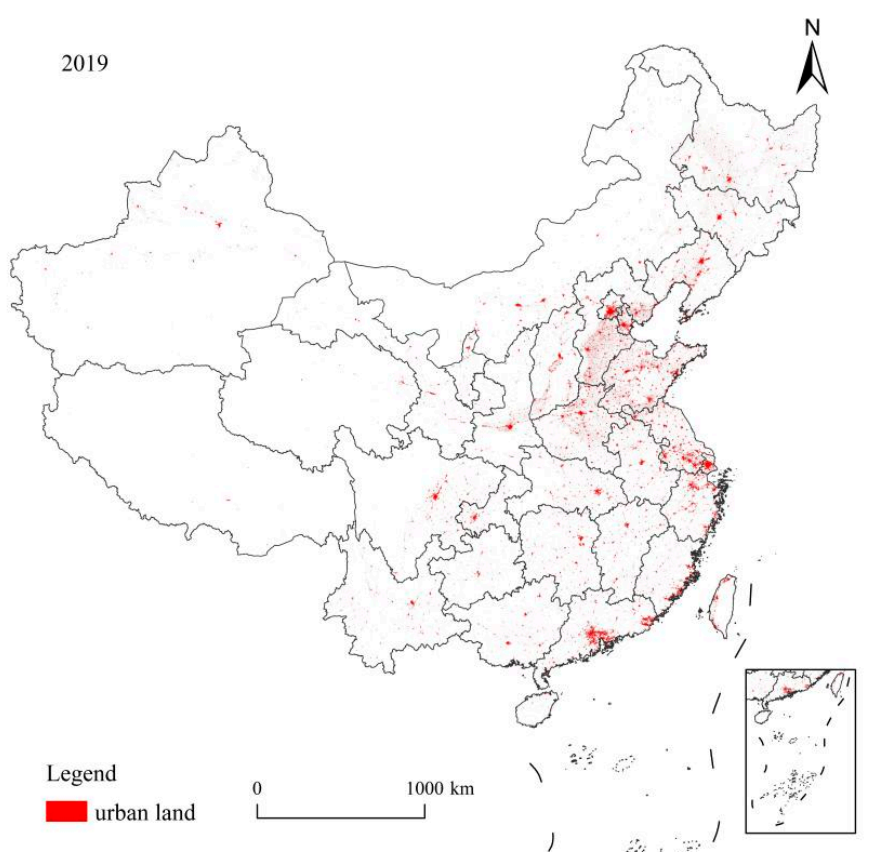

(b)

Figure 3. The distribution of urban land in China.

Five urban agglomerations, including Beijing-Tianjin-Hebei, the Yangtze River Delta, the Pearl River Delta, Chengdu-Chongqing, and the middle reaches of the Yangtze River (Figure 4), were selected for regional statistics (Figure 5). These five urban agglomerations were chosen because they represent typical large urban agglomerations in the north, east, south, west, and central regions of China. The administrative area is $216,000 \mathrm{~km}^{2}$, $358,000 \mathrm{~km}^{2}, 55,368 \mathrm{~km}^{2}, 185,000 \mathrm{~km}^{2}$, and $326,100 \mathrm{~km}^{2}$. According to the China City Statistical Yearbook (2020) [47], the urban population in 2019 was 45,392,400, 70,695,100, $28,733,100,24,414,700$, and 26,525,000, and the GDP in 2019 was 8.4476 billion yuan, 23.62 trillion yuan, 8689.9 billion yuan, 553.1 billion yuan, and 831.25 billion yuan. The Yangtze River Delta is the most developed region in China. Figure 4 was conducted with ArcGIS 10.5.1 software.

The development situation of HSR in the five urban agglomerations is as follows: As of 2019, Beijing-Tianjin-Hebei, the Yangtze River Delta, the Pearl River Delta, ChengduChongqing, and the middle reaches of the Yangtze River have opened 8, 14, 7, 6, and 12 HSR lines, separately. The Yangtze River Delta and the middle reaches of the Yangtze River have many lines and dense stations, and thus they have the most developed HSR networks.

We drew Figure 5 to show the growth rate of the urban land area at different stages (2010-2013, 2013-2016, and 2016-2019). China's urban land growth rate was relatively fast in the period of 2010-2013 and 2016-2019, and there was a short period of slower growth in the period of 2013-2016. From 2010 to 2013, the growth of the Yangtze River Delta had been the most significant. The urban land area growth rate of the Yangtze River Delta and Chengdu-Chongqing exceeded the overall national level. The Pearl River Delta grew very slowly before 2016, and since then it experienced the strongest urban land growth rate. From 2016 to 2019, the urban land area growth rate of the Pearl River 
Delta and the middle reaches of the Yangtze River exceeded the overall national level. It showed that the economic development vitality and urban expansion demand of the Pearl River Delta and middle reaches of the Yangtze River had increased significantly in recent years, and they were in a leading position nationwide. The growth rate of urban land area in Beijing-Tianjin-Hebei had remained stable with a downward trend, which was not prominent across the country. Figure 5 was conducted with Origin2017 software (OriginLab, Massachusetts, America).

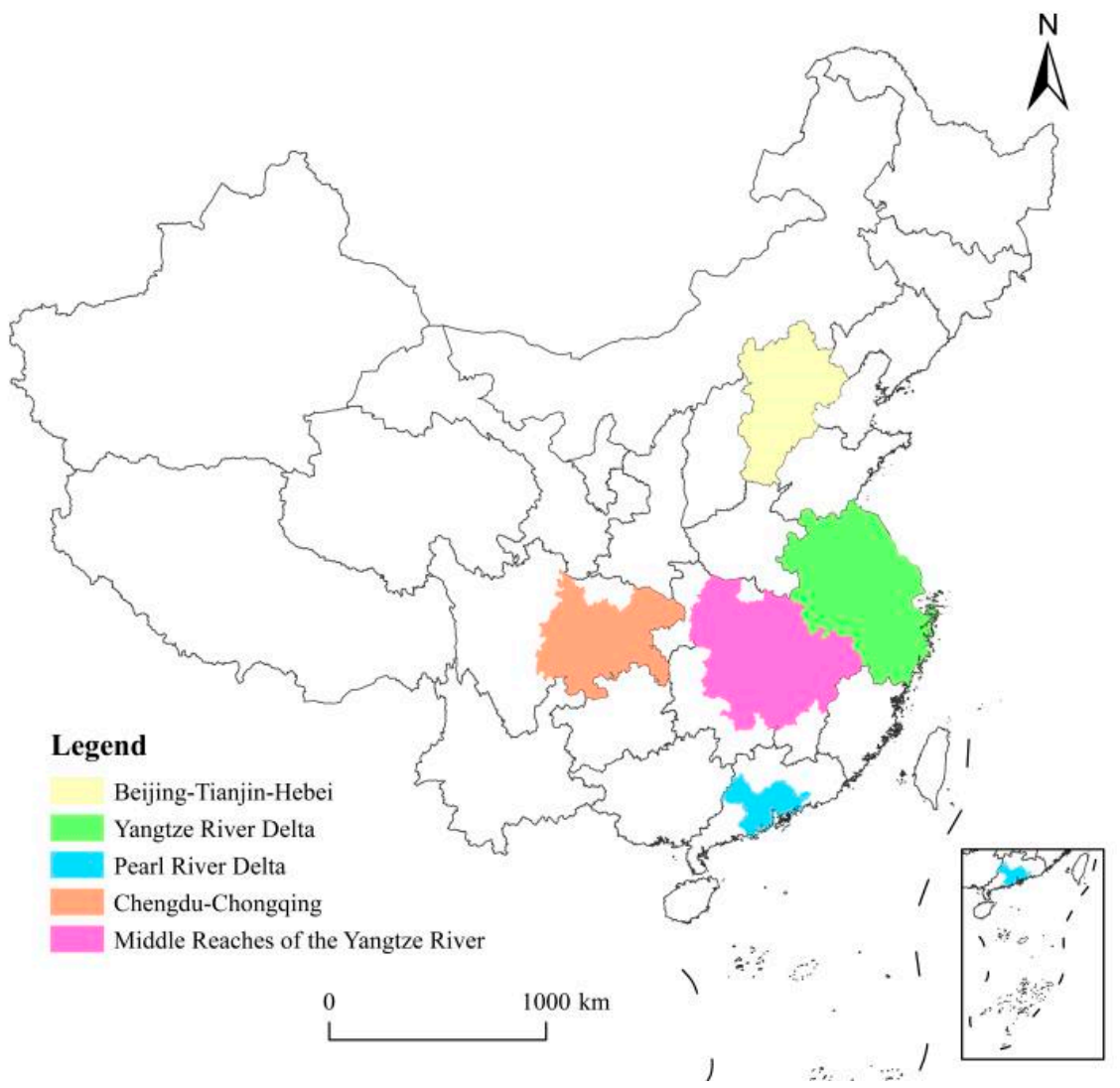

Figure 4. The distribution of five urban agglomerations in China.

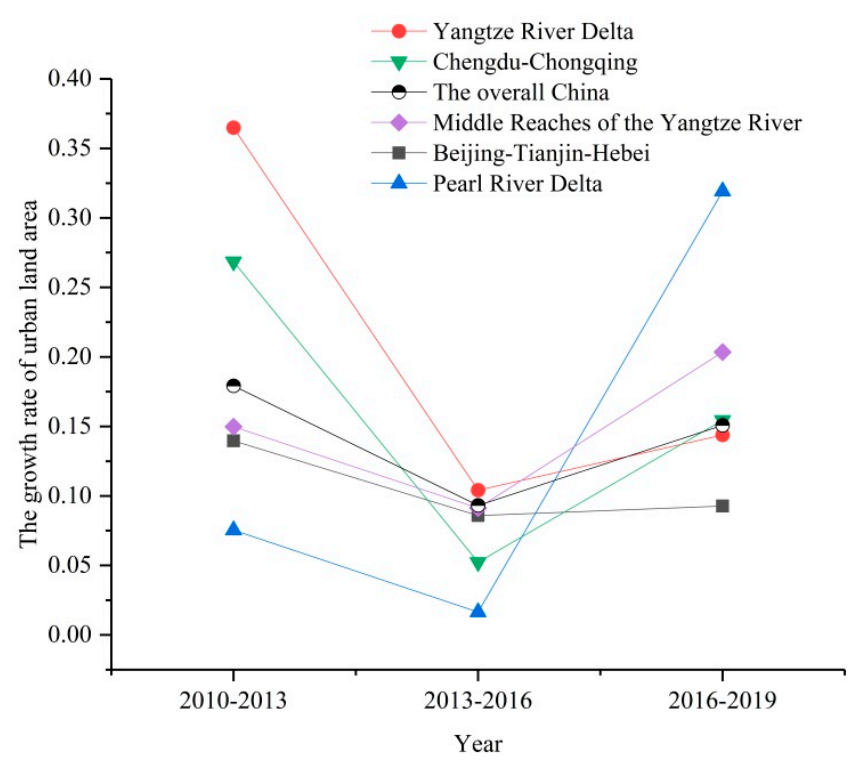

Figure 5. The growth rate of urban land area of overall China and five urban agglomerations in China. 


\subsection{The Regional Heterogeneous Impact of HSR on Urban Expansion in China}

\subsubsection{Parallel Trend Test of the Multi-Stage DID Model}

The results of this section were processed with Stata16.0 software. Before performing the regression of the multi-stage DID model, the multi-collinearity of the model was tested. It was found that, after removing the factor of total retail sales of consumer goods, the multi-collinearity effect is the weakest, and the VIF (variance inflation factor) value of each indicator is below 10. Generally, a VIF value of less than 10 indicates that the multi-collinearity of the model is not significant.

The basic premise of the multi-stage DID model is that the key variables of the treatment group and the control group meet parallel trends before policy implementation. If there is no significant difference between the change of the treatment and control groups before the opening of HSR, a parallel trend hypothesis would be realized, and this model will be unbiased [41]. The formula is as follows:

$$
\begin{aligned}
& \ln \left(\text { urbanarea }_{i t}\right)=\beta_{0}+\beta_{1} \text { openingHSR }{ }_{\mathrm{it}}^{-3}+\beta_{2} \text { openingHSR }_{\mathrm{it}}^{-2}+\ldots \\
& +\beta_{4} \text { openingHSR }_{\mathrm{it}}^{+1}+\ldots+\beta_{7} \text { openingHSR }_{\mathrm{it}}^{+4}+\gamma \sum_{\mathrm{n}} \text { Controls }_{\mathrm{it}}+\mu_{\mathrm{i}}+\mathrm{f}_{\mathrm{t}}+\varepsilon_{\mathrm{it}}
\end{aligned}
$$

where, if $t$ is $j$ years before the opening of HSR in city $i$, then openingHSR $R_{i t}^{-j}$ is assigned the value 1 . Otherwise, the value is 0 . If $t$ is $j$ years after the opening of HSR in city $i$, the value of openingHSR $\mathrm{it}_{\mathrm{it}}^{+\mathrm{j}}$ is 1 . Otherwise, it is $0 . \beta_{1}$ indicates the impact of HSR on urban expansion in 3 years before the opening of HSR, and $\beta_{4}$ indicates the impact of HSR on urban expansion in 1 year after the opening of HSR. The rest of the formula can be deduced by analogy, and the opening year of HSR is the base year. It is worth mentioning that the control variable of the total retail sales of consumer goods at this time has been deleted to avoid multi-collinearity.

It can be seen from Figure 6 that $\beta_{1}, \beta_{2}$, and $\beta_{3}$ are not significantly different from 0 and are not significant at the $5 \%$ level of significance, indicating that the treatment and control group have no significant difference before the opening of HSR. This result proves that the parallel trend test has been passed.

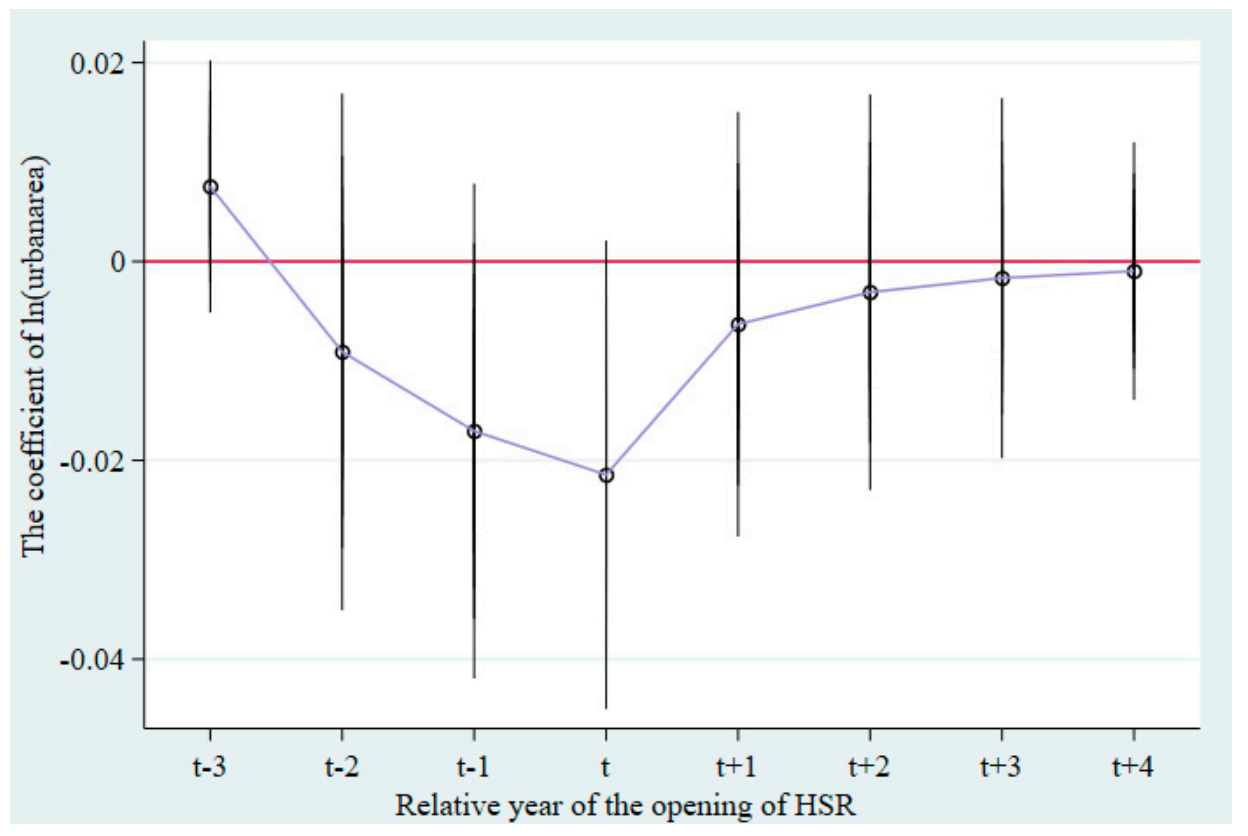

Figure 6. Parallel trend test. 


\subsubsection{The Overall Impact of HSR on Urban Expansion in China}

Comparing columns (1)-(3) of Table 2 (the values in parenthesis are the standard deviations of the corresponding independent variables, the same as below), it can be seen that before the control variables are added, although the impact of the opening of HSR on urban expansion has a promoting effect, the results are not significant. After adding the control variables, the opening of HSR has a significant positive impact on urban expansion, which indicates that under certain socio-economic conditions, the opening of HSR significantly promotes the urban expansion. It can be seen from column (2) in Table 2 (where openingHSR_1 represents 1 year after the opening of HSR) that the opening of HSR had no effect on urban expansion several years after opening, which is opposite to the result of whether HSR opened or not. The reason for this trend may be that the first opening of HSR provided motivation for urban expansion, but that the impact of HSR in the following several years on urban land gradually weakened. This result can also be seen from the regression coefficients in column (2) in Table 2. HSR promotes the accumulation of various resources in cities, and the function of urban land has undergone a drastic evolution. However, urban land does not show a significant expansion trend. Connotative growth is the main development direction of cities after the first opening of HSR. HSR frequency has a significantly negative impact on urban expansion. The reason for this result may be that the cities with higher HSR frequency are often large cities such as provincial or sub-provincial capital cities. These cities already have large areas of urban land due to their rapid early development. Therefore, the potential for urban expansion of these cities is small and the extent of urban expansion is limited, meaning that HSR frequency does not promote urban expansion. It can be concluded that the first opening of HSR has a more significant role in promoting urban expansion than HSR frequency (Table 2).

Table 2. The overall impact of HSR on urban expansion in China.

\begin{tabular}{|c|c|c|c|}
\hline Variables & $\begin{array}{c}\ln (\text { Urbanarea) } \\
\text { (1) }\end{array}$ & (2) & (3) \\
\hline openingHSR & $\begin{array}{c}0.016 \\
(0.010)\end{array}$ & $\begin{array}{c}0.013 \\
(0.010)\end{array}$ & $\begin{array}{l}0.026^{* *} \\
(0.012)\end{array}$ \\
\hline openingHSR_1 & & $\begin{array}{c}-0.427^{* * * *} \\
(0.015)\end{array}$ & \\
\hline openingHSR_2 & & $\begin{array}{c}-0.374^{* * *} \\
(0.013)\end{array}$ & \\
\hline openingHSR_3 & & $\begin{array}{c}-0.320 * * * \\
(0.011)\end{array}$ & \\
\hline openingHSR_4 & & $\begin{array}{c}-0.252 * * * \\
(0.009)\end{array}$ & \\
\hline openingHSR_5 & & $\begin{array}{l}-0.196^{* * *} \\
(0.007)\end{array}$ & \\
\hline openingHSR_6 & & $\begin{array}{c}-0.166^{* * *} \\
(0.007)\end{array}$ & \\
\hline openingHSR_7 & & $\begin{array}{c}-0.161^{* * *} \\
(0.007)\end{array}$ & \\
\hline openingHSR_8 & & $\begin{array}{l}-0.084^{* * * *} \\
(0.004)\end{array}$ & \\
\hline openingHSR_9 & & $\begin{array}{c}-0.030 * * * \\
(0.006)\end{array}$ & \\
\hline GDP & & & $\begin{array}{l}0.087^{*} \\
(0.052)\end{array}$ \\
\hline perGDP & & & $\begin{array}{c}0.004 \\
(0.010)\end{array}$ \\
\hline
\end{tabular}


Table 2. Cont.

\begin{tabular}{|c|c|c|c|}
\hline Variables & $\begin{array}{c}\text { ln(Urbanarea) } \\
\text { (1) }\end{array}$ & (2) & (3) \\
\hline added value of the secondary industry & & & $\begin{array}{l}-0.003 \\
(0.005)\end{array}$ \\
\hline added value of the tertiary industry & & & $\begin{array}{c}0.002 \\
(0.004)\end{array}$ \\
\hline industry & & & $\begin{array}{c}-0.0002 \\
(0.006)\end{array}$ \\
\hline HSR frequency & & & $\begin{array}{c}-0.0222^{* *} \\
(0.011)\end{array}$ \\
\hline constant & $\begin{array}{c}-88.333^{* * *} \\
(3.359)\end{array}$ & $\begin{array}{c}5.899 * * * \\
(0.011)\end{array}$ & $\begin{array}{c}-86.598^{* * * *} \\
(3.311)\end{array}$ \\
\hline City (fixed effect) & yes & yes & yes \\
\hline Year (fixed effect) & yes & yes & yes \\
\hline Observations & 2300 & 2300 & 2300 \\
\hline $\mathrm{R}^{2}$ & 0.756 & 0.767 & 0.760 \\
\hline
\end{tabular}

\subsubsection{The Impact of HSR on Urban Expansion for Five Urban Agglomerations}

The results in Table 2 show the overall impact of HSR on urban expansion of prefecturelevel cities in China. However, China is a country with a vast land area and strong regional heterogeneity. Therefore, this paper chose the urban agglomerations of Beijing-TianjinHebei, the Yangtze River Delta, the Pearl River Delta, Chengdu-Chongqing and the middle reaches of the Yangtze River to discuss the heterogeneous impact of HSR on urban expansion in China. It can be seen from Table 3 that the opening of HSR only had a significant positive impact on urban expansion in the Beijing-Tianjin-Hebei urban agglomeration. The reason for this result may be that the opening of HSR brought opportunities for relatively less developed cities such as Baoding and Chengde. These cities rely on efficient transportation, manpower and material resources, and large-scale land development brought by HSR. Compared with other urban agglomerations, the relative development level of different cities in the Beijing-Tianjin-Hebei urban agglomeration is quite different. Some of the less developed cities have been siphoned by developed cities for a long time, meaning that there were fewer development opportunities and a low motivation for urban expansion. However, the emergence of HSR greatly promotes the rapid expansion of these cities. The development differences between the cities among the other four urban agglomerations are not as big as the Beijing-Tianjin-Hebei urban agglomeration. Therefore, the emergence of HSR has not caused the small and medium-sized cities in these four urban agglomerations to expand significantly.

As mentioned above, the first opening of HSR has a significant role in promoting the urban expansion of cities with lagging development. HSR frequency has a significant negative impact on urban expansion in the Beijing-Tianjin-Hebei urban agglomeration, with higher HSR frequency leading to a smaller urban land area. There is a relatively low HSR frequency in small and medium-sized cities, so HSR frequency restrains the urban expansion in Beijing-Tianjin-Hebei. Compared with HSR frequency, the opening of HSR has a more significant positive impact on urban expansion in Beijing-Tianjin-Hebei. HSR frequency has a significant positive impact on urban expansion in the Yangtze River Delta, with higher HSR frequency correlated to a larger urban land area. The reason for this trend may be that the Yangtze River Delta has relatively high development potential due to the coastal location and it includes large cities such as Hefei, Nanjing, Shanghai, Hangzhou, Ningbo, Suzhou, and others. Increased HSR frequency has brought good development opportunities, promoted the accumulation of human and material resources in cities, and strengthened the circulation between the cities, which significantly promoted urban expansion. 
Table 3. The impact of HSR on urban expansion in five urban agglomerations in China.

\begin{tabular}{|c|c|c|c|c|c|}
\hline Variables & $\ln ($ urbanarea) & & & & \\
\hline $\begin{array}{c}\text { Urban } \\
\text { Agglomeration }\end{array}$ & $\stackrel{(4)}{\text { Beijing-Tianjin-Hebei }}$ & $\begin{array}{c}\text { (5) } \\
\text { Yangtze River Delta }\end{array}$ & $\begin{array}{c}\text { (6) } \\
\text { Pearl River Delta }\end{array}$ & $\stackrel{(7)}{\text { Chengdu-Chongqing }}$ & $\begin{array}{l}(8) \\
\text { Middle Reaches of } \\
\text { the Yangtze River }\end{array}$ \\
\hline openingHSR & $0.045^{*}$ & -0.034 & 0.0003 & -0.017 & -0.024 \\
\hline \multirow{2}{*}{ GDP } & $\begin{array}{c}(0.024) \\
0.018\end{array}$ & $\begin{array}{l}(0.024) \\
-0.236^{* * *}\end{array}$ & $\begin{array}{l}(0.026) \\
-0.082\end{array}$ & $\begin{array}{c}(0.0 \angle 4) \\
0.200\end{array}$ & $\begin{array}{l}(0.018) \\
-0.126\end{array}$ \\
\hline & $(0.035)$ & $(0.084)$ & $(0.060)$ & $(0.142)$ & $(0.192)$ \\
\hline \multirow{2}{*}{ perGDP } & -0.059 & 0.022 & 0.010 & -0.164 & -0.021 \\
\hline & $(0.053)$ & $(0.022)$ & $(0.007)$ & $(0.108)$ & $(0.024)$ \\
\hline added value of the & 0.003 & 0.001 & -0.006 & $0.044^{* *}$ & -0.002 \\
\hline secondary industry & $(0.023)$ & $(0.017)$ & $(0.009)$ & $(0.193)$ & $(0.002)$ \\
\hline added value of the & 0.015 & 0.009 & -0.007 & -0.038 & -0.009 \\
\hline tertiary industry & $(0.010)$ & $(0.010)$ & $(0.005)$ & $(0.023)$ & $(0.017)$ \\
\hline \multirow{2}{*}{ industry } & -0.008 & 0.035 * & -0.024 & -0.038 & $0.064^{* * *}$ \\
\hline & $(0.004)$ & $(0.018)$ & $(0.019)$ & $(0.023)$ & $(0.021)$ \\
\hline \multirow{2}{*}{ HSR frequency } & $-0.030^{* *}$ & 0.048 * & -0.010 & -0.003 & 0.020 \\
\hline & $(0.013)$ & $(0.028)$ & $(0.011)$ & $(0.017)$ & $(0.015)$ \\
\hline constant & $-61.368^{* * *}$ & $-121.766^{* * *}$ & $-55.122 * * *$ & $-90.871^{* * *}$ & $-95.929 * * *$ \\
\hline constant & (9.135) & (8.736) & $(8.412)$ & $(10.535)$ & $(6.031)$ \\
\hline City (fixed effect) & yes & yes & yes & yes & yes \\
\hline Year (fixed effect) & yes & yes & yes & yes & yes \\
\hline Observations & 130 & 400 & 90 & 100 & 240 \\
\hline $\mathrm{R}^{2}$ & 0.856 & 0.853 & 0.823 & 0.875 & 0.916 \\
\hline
\end{tabular}

Note: ${ }^{* * *}, * *$ and ${ }^{*}$ respectively mean that $p$-value of the variable is less than $0.01,0.05$, and 0.1 .

\subsubsection{The Impact of HSR on Urban Expansion for Cities of Different Sizes}

City size is defined according to the urban population and is divided into large, medium, and small cities to explore the heterogeneous impact of HSR on urban expansion for cities of different sizes. What needs to be pointed out is that the urban resident population is less than 500,000 in small cities, 500,000 to 1 million in medium-sized cities, and more than 1 million in large cities [55]. Comparing columns (9)-(11) in Table 4, it can be seen that HSR frequency only has a significant negative impact on the urban expansion of small cities. The reason for this result may be that large numbers of people from small cities migrate to medium and large cities. Small cities experience the siphon effect of HSR, and the production factors are greatly reduced. Therefore, small cities lack the driving force for urban expansion, and their expansion speed and intensity are relatively low. The opening of HSR has no significant impact on urban expansion of the three size categories of cities. Combining the results in Table 2, the opening of HSR has no significant impact on the heterogeneity of urban expansion for cities of different sizes. The first opening of HSR has not significantly promoted or inhibited urban expansion for cities of different sizes. By comparing these results with the significance of other socio-economic factors, it can be concluded that factors such as GDP have a more significant influence on urban expansion of cities of different sizes than the opening of HSR.

Table 4. The impact of HSR on urban expansion of the cities of different sizes in China.

\begin{tabular}{cccc}
\hline Variables & $\begin{array}{c}\ln \text { (Urbanarea) } \\
\text { (9) Small Cities }\end{array}$ & (10) Medium-Sized Cities & (11) Large Cities \\
\hline \multirow{2}{*}{ openingHSR } & 0.035 & -0.007 & 0.021 \\
& $(0.025)$ & $(0.014)$ & $(0.019)$ \\
GDP & -0.027 & $-0.375^{* *}$ & 0.023 \\
& $(0.206)$ & $(0.162)$ & $(0.036)$ \\
perGDP & -0.014 & $0.058^{*}$ & $0.017^{*}$ \\
added value of the & $(0.023)$ & $(0.031)$ & $(0.010)$ \\
secondary industry & -0.00005 & 0.014 & -0.005 \\
added value of the & $(0.005)$ & $(0.009)$ & $(0.010)$ \\
tertiary industry & -0.007 & -0.002 & 0.003 \\
industry & $(0.016)$ & $(0.003)$ & $(0.005)$ \\
& -0.032 & $0.081 * * *$ & -0.000 \\
\end{tabular}


Table 4. Cont.

\begin{tabular}{cccc}
\hline Variables & $\begin{array}{c}\text { ln(Urbanarea) } \\
\text { (9) Small Cities }\end{array}$ & (10) Medium-Sized Cities & (11) Large Cities \\
\hline HSR frequency & $-0.069^{* *}$ & 0.015 & -0.012 \\
& $(0.034)$ & $(0.022)$ & $(0.012)$ \\
constant & $-94.189^{* * *}$ & $-91.348^{* * *}$ & $-80.386^{* * *}$ \\
City fixed effect & $(7.279)$ & $(0.022)$ & $(4.953)$ \\
Year fixed effect & yes & yes & yes \\
Observations & 740 & yes & yes \\
$R^{2}$ & 0.768 & 0.826 & 800 \\
\hline
\end{tabular}

Note: ${ }^{* * *}{ }^{* *}$, and ${ }^{*}$ respectively mean that $p$-value of the variable is less than $0.01,0.05$, and 0.1 .

\subsubsection{Robustness Test of the Multi-Stage DID Model}

A change of urban built-up areas can also represent urban expansion. Therefore, the indicator of urban built-up areas is used to replace the area of urban land for a robustness test that uses dependent variable substitution. The data for the value of urban built-up areas were sourced from the China Urban Construction Statistical Yearbook from 2010 to 2019 [15] and were calculated using logarithmic processing.

$$
\ln \left(\text { built }- \text { up_area }_{i t}\right)=\beta_{0}+\beta_{1} \text { openingHSR }_{\text {it }}+\gamma \sum_{\mathrm{n}} \text { Controls }_{\text {it }}+\mu_{\mathrm{i}}+\mathrm{f}_{\mathrm{t}}+\varepsilon_{\mathrm{it}}
$$

Haidong City in Qinghai Province was deleted from the sample due to significant missing data. Comparing Table 5 and column (2) in Table 2, it can be seen that the two results are extremely similar. When no control variables are added, the opening of HSR does not significantly promote the expansion of urban land or built-up areas. Several years after the opening, HSR has a significant negative impact on the expansion of built-up areas of a city, and this impact gradually weakens over time. Therefore, it was believed that the model passed the robustness test.

Table 5. The result of robustness test.

\begin{tabular}{|c|c|}
\hline Variables & $\begin{array}{c}\ln \text { (Build-Up Areas) } \\
-12\end{array}$ \\
\hline openingHSR & $\begin{array}{c}0.009 \\
-0.013\end{array}$ \\
\hline openingHSR_1 & $\begin{array}{c}-0.418^{* * *} \\
-0.017\end{array}$ \\
\hline openingHSR_2 & $\begin{array}{c}-0.348^{* * *} \\
-0.016\end{array}$ \\
\hline openingHSR_3 & $\begin{array}{c}-0.296^{* * *} \\
-0.015\end{array}$ \\
\hline openingHSR_4 & $\begin{array}{c}-0.243^{* * *} \\
-0.014\end{array}$ \\
\hline openingHSR_5 & $\begin{array}{c}-0.199 * * * \\
-0.012\end{array}$ \\
\hline openingHSR_6 & $\begin{array}{c}-0.138^{* * *} \\
-0.011\end{array}$ \\
\hline openingHSR_7 & $\begin{array}{c}-0.088^{* * *} \\
-0.009\end{array}$ \\
\hline openingHSR_8 & $\begin{array}{c}-0.056^{* * *} \\
-0.007\end{array}$ \\
\hline openingHSR_9 & $\begin{array}{c}-0.025^{* * *} \\
-0.004\end{array}$ \\
\hline constant & $\begin{array}{c}4.825^{* * *} \\
-0.015\end{array}$ \\
\hline
\end{tabular}


Table 5. Cont.

\begin{tabular}{cc} 
Variables & $\begin{array}{c}\mathbf{l n} \text { (Build-Up Areas) } \\
\mathbf{- 1 2}\end{array}$ \\
\hline City fixed effect & yes \\
Year fixed effect & yes \\
Observations & 2290 \\
$\mathrm{R}^{2}$ & 0.636 \\
\hline Note: ${ }^{* * *}$ means that $p$-value of the variable is less than 0.01.
\end{tabular}

\subsection{The Type Heterogeneous Impact of HSR on Urban Expansion in China}

3.3.1. The Impact of the First Opening of HSR on the Conversion of Non-Urban Land to Urban Land

Urban land expansion is the process of urban land invading non-urban land, and the conversion of different types of non-urban land to urban land is a manifestation of urban expansion. Analogous to Equation (1), we divided cities into treatment group and control group based on whether HSR was opened or not, which reflects the heterogeneous impact of the first opening of HSR on the conversion of different types of non-urban land to urban land. The dependent variables are as follows: the area of barren land converted to urban land, the area of water body converted to urban land, the area of vegetation cover converted to urban land, and the area of cultivated land converted to urban land. The regression results can be seen in Table 6 .

Table 6. The impact of the first opening of HSR on the conversion of non-urban land to urban land.

\begin{tabular}{|c|c|c|c|c|}
\hline Variable & $\begin{array}{l}\text { (13) } \\
\text { The Area of Barren Land } \\
\text { Converted to Urban Land }\end{array}$ & $\begin{array}{l}\text { (14) } \\
\text { The Area of Water Body } \\
\text { Converted to Urban Land }\end{array}$ & $\begin{array}{l}(15) \\
\text { The Area of Vegetation Cover } \\
\text { Converted to Urban Land }\end{array}$ & $\begin{array}{l}\text { (16) } \\
\text { The Area of Cultivated Land } \\
\text { Converted to Urban Land }\end{array}$ \\
\hline openingHSR & $\begin{array}{c}-0.138^{* * *} \\
(0.050)\end{array}$ & $\begin{array}{c}-0.057^{* *} \\
(0.029)\end{array}$ & $\begin{array}{c}0.007 \\
(0.030)\end{array}$ & $\begin{array}{l}0.104 * \\
(0.062)\end{array}$ \\
\hline constant & $\begin{array}{c}-0.508^{* * *} \\
(0.033)\end{array}$ & $\begin{array}{c}-0.383^{* * *} \\
(0.019)\end{array}$ & $\begin{array}{c}-0.132 * * * \\
(0.019)\end{array}$ & $\begin{array}{c}-0.080 * * \\
(0.040)\end{array}$ \\
\hline City (fixed effect) & yes & yes & yes & yes \\
\hline Year (fixed effect) & yes & yes & yes & yes \\
\hline Observations & 2300 & 2300 & 2300 & 2300 \\
\hline $\mathrm{R}^{2}$ & 0.013 & 0.001 & 0.000 & 0.003 \\
\hline
\end{tabular}

Note: ${ }^{* * *}, * *$, and ${ }^{*}$ respectively mean that $p$-value of the variable is less than $0.01,0.05$, and 0.1 .

The first opening of HSR will promote the conversion of vegetation cover and cultivated land to urban land, but it cannot promote the conversion of barren land and water body to urban land. It shows that, as a whole, under the opportunity of the opening of HSR, the expansion of urban land is mainly based on vegetation cover and cultivated land as the main source.

3.3.2. The Spatial Differences of the Impact of the First Opening of HSR on the Conversion of Non-Urban Land to Urban Land

The results in Table 6 only show that the first opening of HSR promotes the scale of the conversion of vegetation cover and cultivated land to urban land. However, China's land has complex heterogeneity characteristics. The results in Table 6 cannot reflect the spatial differences of the impact of HSR on the conversion of non-urban land to urban land. Therefore, the next step is to visualize the impact of the first opening of HSR on the conversion of different types of non-urban land to urban land in the form of maps. This can reveal and compare the conversion of various kinds of non-urban land to urban land after the first opening of HSR in cities in different regions.

From column (3) in Table 2 it can be seen that the first opening of HSR in a city has a significantly positive effect on urban expansion. Therefore, we selected the cities that opened HSR for the first time between 2010 and 2019 and studied the characteristics of urban expansion by calculating the conversion of different types of non-urban land to 
urban land in 1 year before HSR was opened and the year when HSR was opened. Figure 7 shows the area converted from non-urban land to urban land in each city in the opening year and the previous year of HSR. The area converted from barren land to urban land was the lowest, and the area converted from cultivated land to urban land was the highest. This result shows that cultivated land is the main type of land that is converted due to urban land expansion after the first opening of HSR. Figure 7 was conducted with ArcGIS 10.5.1 software.

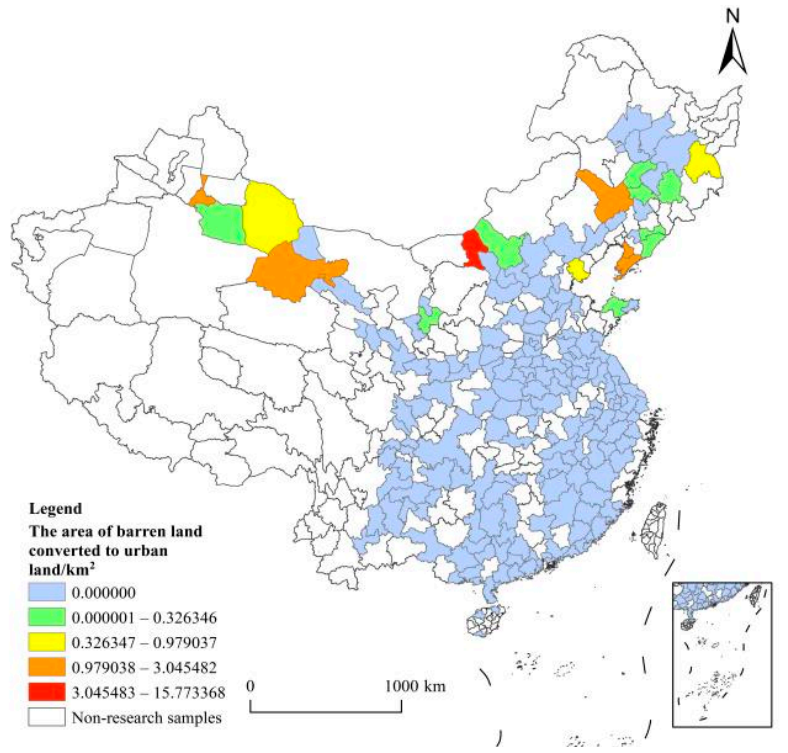

(a)

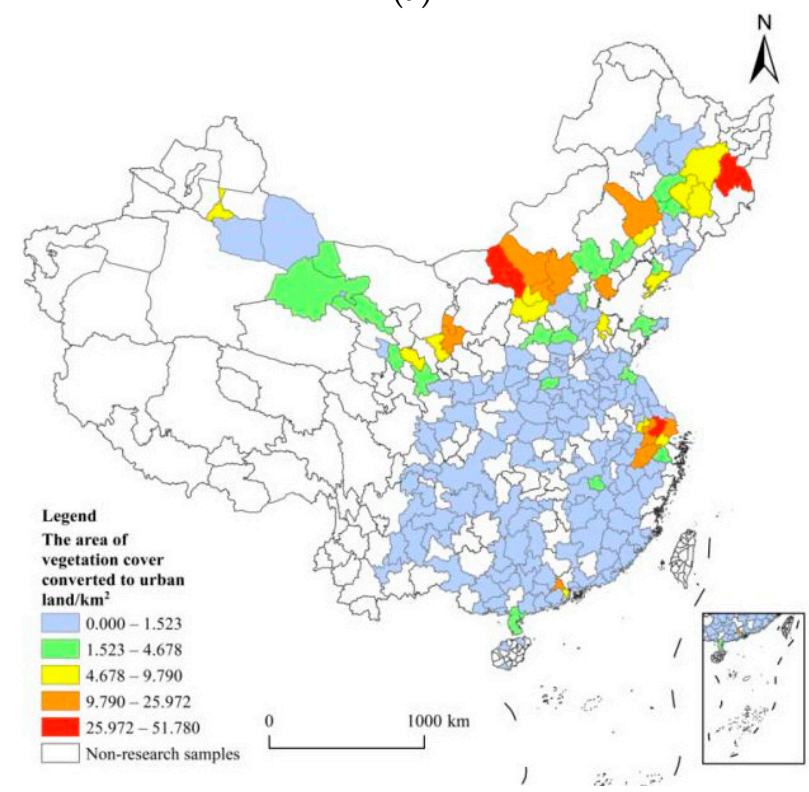

(c)

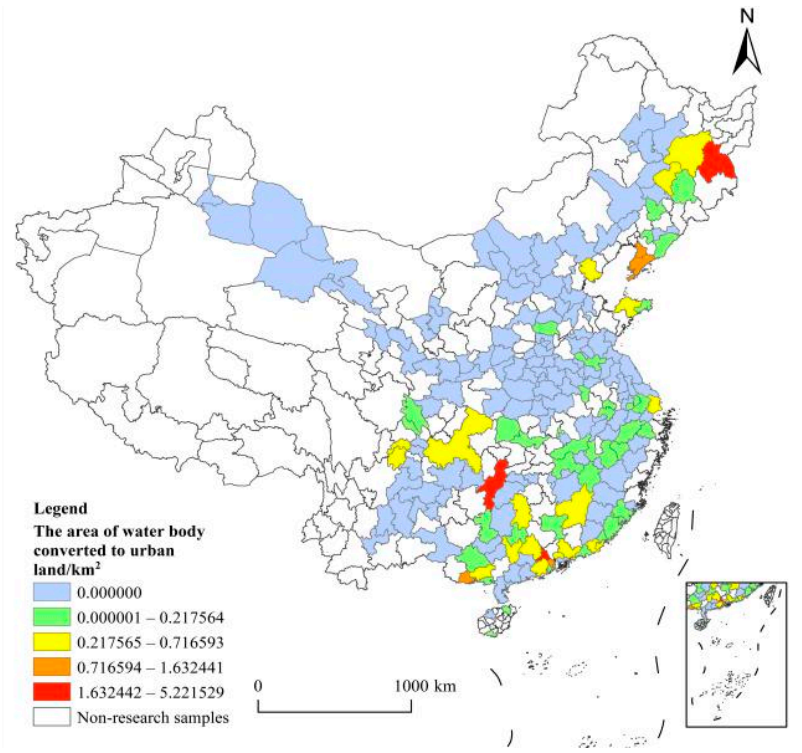

(b)

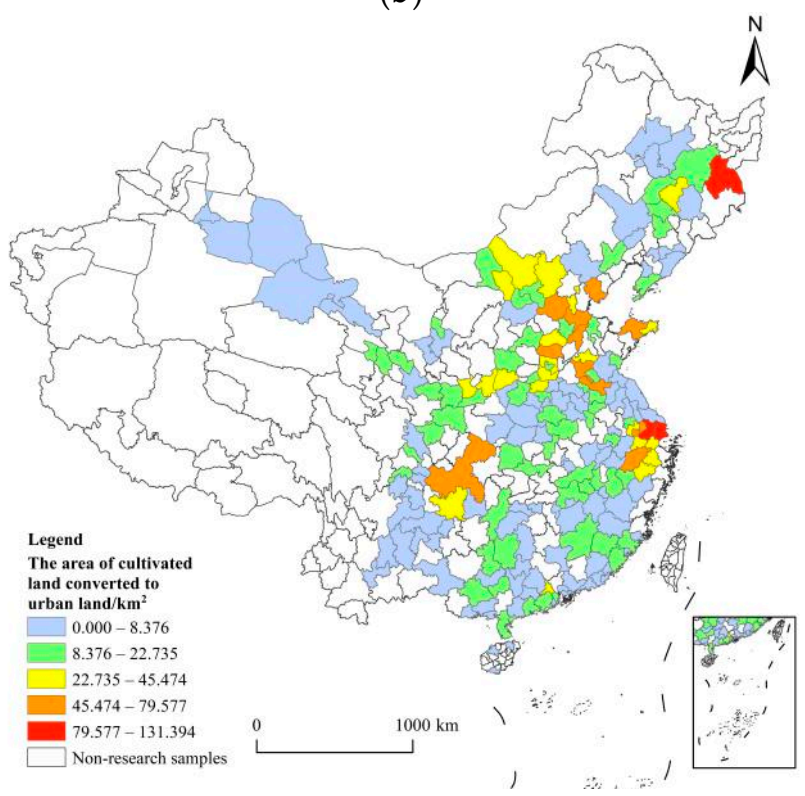

(d)

Figure 7. The area of non-urban land converted to urban land in the cities that first opened HSR during 2010 to 2019. (a) The area of barren land converted to urban land; (b) the area of water body converted to urban land; (c) the area of vegetation cover converted to urban land; (d) the area of cultivated land converted to urban land.

For the results to be comparable, the proportion of the area of different types of nonurban land that are converted into urban land relative to the area of all non-urban land that are converted into urban land is calculated in a city (Figure 8). Comparing Figure 8a-d, the first opening of HSR has enabled most cities to achieve urban expansion by converting cultivated land to urban land. The proportion of vegetation cover converted to urban 
land ranks second, showing that large areas of ecosystems such as forests and grassland are converted into urban areas. The proportion of barren land and water body converted to urban land is the lowest and does not exceed 1\%. Cities with a large proportion of barren land converted to urban land are concentrated in Xinjiang and the Inner Mongolia autonomous region. Urban expansion in these areas is mainly based on the occupation of vegetation cover and barren land, while the occupation of cultivated land is lower (Figure $8 c-d$ ). The reason for this result may be due to the geographical location of these regions, with expansive areas of deserts, barren land, and grassland but limited areas of cultivated land. The development opportunities brought by HSR led these cities to expand into barren land and vegetation cover land. China has proposed a rural revitalization strategy. Cultivated land is the main source of industrial development for residents in northwestern China and Inner Mongolia. Even the first opening of HSR, which has a significant impact on urban expansion, has not prompted a large amount of cultivated land to be converted to urban land. Comparing Figure $8 \mathrm{c}$,d, we can see that the conversion area of vegetation cover land to urban land in the cities in northeastern China is more apparent. In some cities, the proportion of vegetation cover and cultivated land conversion to urban land is roughly equal. The reason for this trend may be that the Northeast region is the area with a relatively large scale of grain production. Although the opening of HSR will cause some cultivated land to be converted, for the sake of national food security, urban expansion in Northeast China needs to expand into vegetation cover land to meet the needs of urban development. It can be seen from Figure 8c that the first opening of HSR in the southern cities has caused less conversion of vegetation cover land than that in northern cities. This trend is opposite to the patterns of vegetation cover between northern and southern China. The reason for this result may be that China is paying increasing attention to the ecological and environmental importance of vegetation cover. However, much of the vegetation cover in the north is of little significance to the ecological environment, so the first opening of HSR has prompted urban expansion in the north to occupy more vegetation cover land. Figure 8 was conducted with ArcGIS 10.5.1 software.

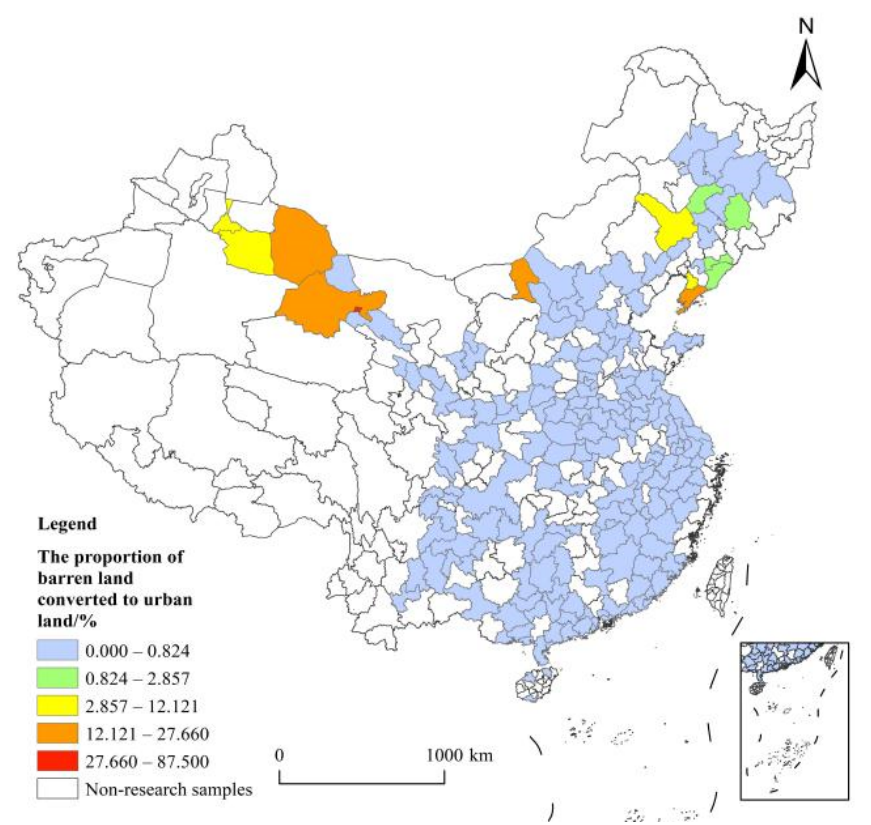

(a)

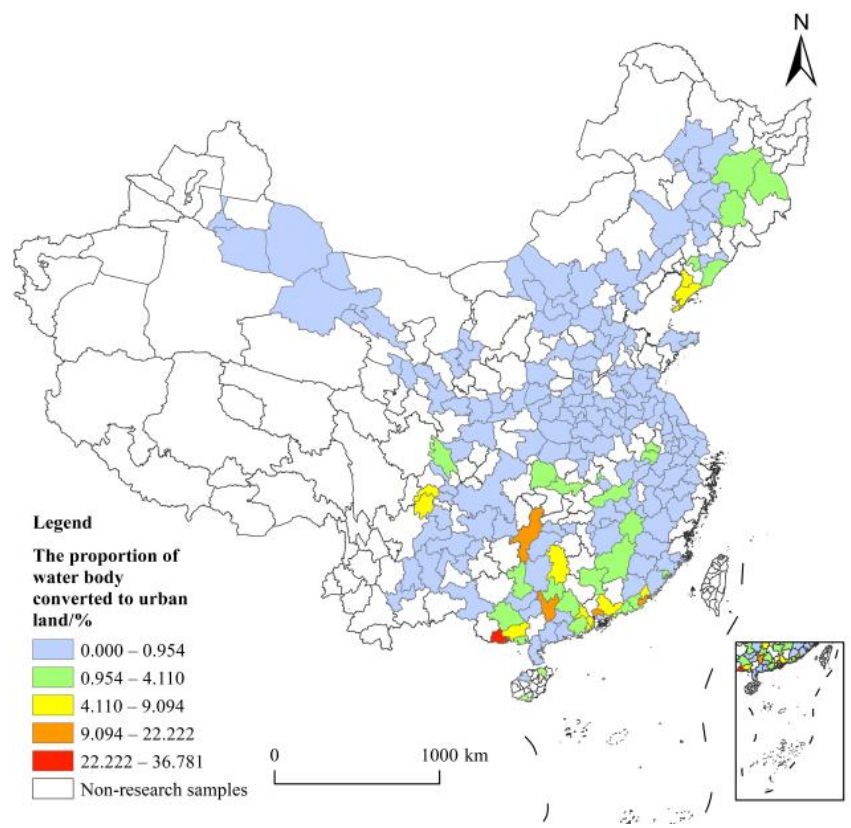

(b)

Figure 8. Cont. 


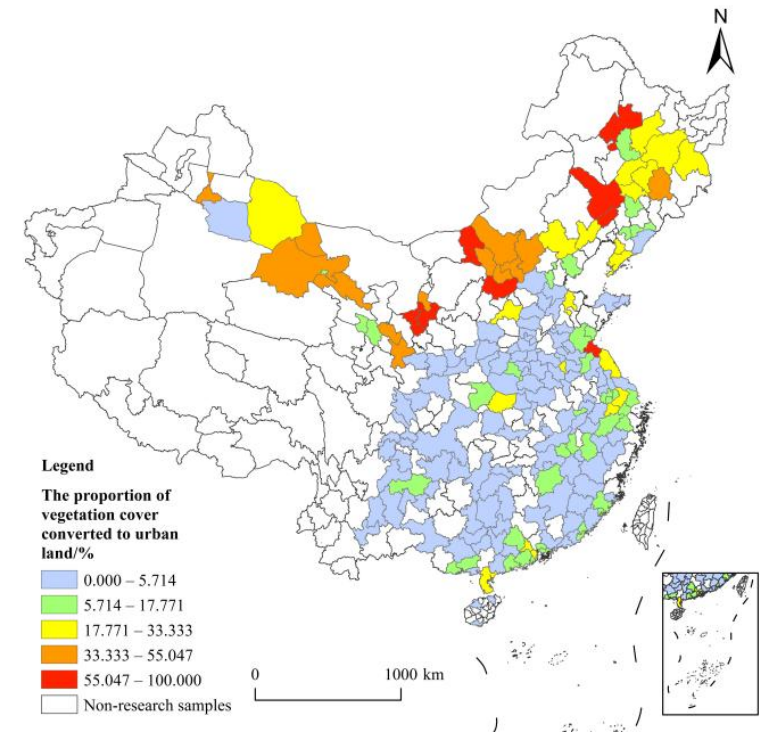

(c)

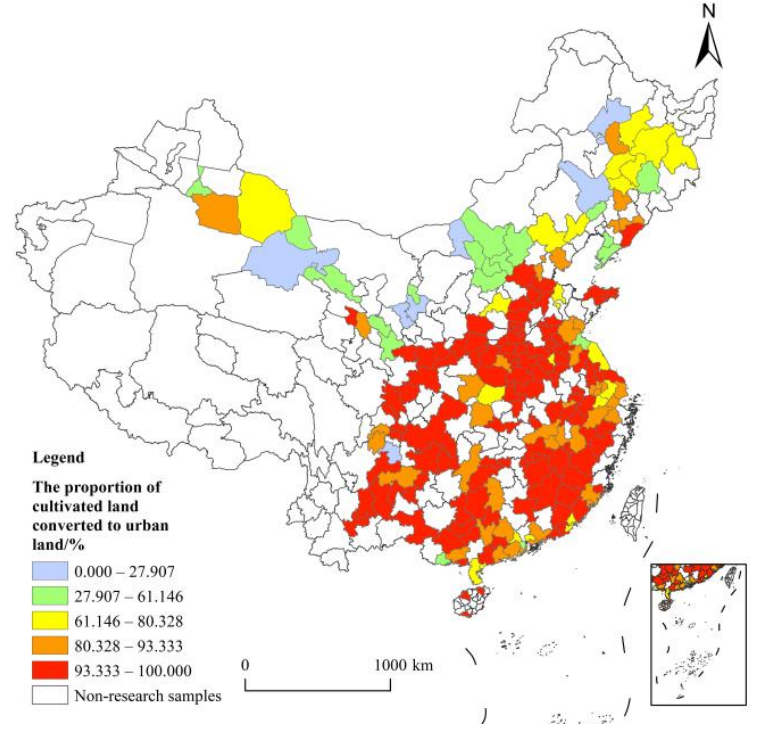

(d)

Figure 8. The proportion of non-urban land converted to urban land in the cities that first opened HSR during 2010 to 2019. (a) The proportion of barren land converted to urban land; (b) the proportion of water body converted to urban land; (c) the proportion of vegetation cover converted to urban land; (d) the proportion of cultivated land converted to urban land.

\section{Discussion}

This study explores the impact of HSR on urban expansion in China and discusses the heterogeneous impact of HSR opening and HSR frequency for different regions.

\subsection{Discussion of Results}

Compared with previous research [29,41-43], this study shows that the opening of HSR has a less significant role in promoting urban expansion in China, regardless of the different districts and city groups of different sizes. For example, in the results of this paper, none of the regression coefficients with the opening of HSR are significantly less than 0.01. This result contrasts with studies such as [42], who found that the opening of HSR is often associated with regression coefficients less than 0.01 . In addition, Table 2 shows that HSR have a negative impact on urban expansion several years after the operation of HSR, while the results of Zhu et al. [41] and Deng et al. [43] show that the opening of HSR has a positive effect on urban expansion several years after the opening of HSR. The reasons for the difference between these results may be:

(1) The data source. We used the European Space Agency land use data, and different data sources may have different divisions of urban land and different accuracy. For example, different data sources have different criteria for dividing urban land. In addition, the accuracy of the data of the European Space Agency is about 71\% [51], and the accuracy of other data sources may be higher or lower. Moreover, selecting the difference of the old and new research period may also be a reason. Niu et al. [42] adopted night-time light data, and the research area of this paper is relatively new (the research period is from 2010 to 2019). China's expressways and civil aviation systems are also developing, meaning that the speed advantage of HSR may no longer be as significant as before. Therefore, the impact of the emergence of HSR on urban expansion is also weakening today.

(2) In addition, major national policies and the delineation of new economic zones may have a more significant role in promoting urban expansion than the emergence of HSR. Compared with previous studies [3,29,41-43], this research on the impact of HSR on urban expansion is not limited to urban land but further explores the impact of the opening of HSR on the conversion of different types of non-urban land to urban land. The results confirm that the first opening of HSR has significant regional 
differences in the impact of various types of non-urban land that are converted to urban land. The results can provide valuable information for urban land planning and management in the cities that are about to open HSR.

Some progress has been made in the European case of the impact of HSR on urban land use. European research results tend to be refined analyses within a certain buffer zone of HSR stations or corridors $[13,14,28,35]$, while the results of this research are based on the macro-scale of cities. Shen et al. [28] found that HSR stations in Madrid had improved regional accessibility and promoted urban expansion. Our results in Table 1 show that the opening of HSR has promoted urban expansion, which has certain similarities. Shen et al. [14] found that HSR changes the accessibility and has a completely different impact on the land development of large cities and small cities. However, our research results show that no matter whether it is the opening of HSR or HSR frequency, there is no significant difference in the impact of urban expansion between large cities and small cities. The reason may be related to the number of samples, or the city size has different standards in different countries. Wenner et al. [35] found that HSR stations at different distances from the city center have different urban land distribution intensities within the buffer zone. Our results also found that the opening of HSR and HSR frequency have a heterogeneous impact on urban expansion of different urban agglomerations and cities of different sizes. In general, compared with the European case, our research did not consider the accessibility of cities, and the research scale was more macroscopic, but we also obtained some similar conclusions.

\subsection{Limitations}

The limitations of this research are as follows:

(1) Our research only considered the first opening of HSR. However, China will build multiple HSR lines and stations in the future, and many cities have already opened multiple HSR routes. Therefore, the opening of multiple HSR lines may cause a difference to the impact of the first opening of HSR on urban expansion, and there may be regional differences. For example, an HSR line can be taken as an example to compare urban expansion differences between the cities with other HSR lines opening and the cities without new HSR lines opening.

(2) The national HSR transportation system has already formed a network, and an HSR network can be built based on passenger flow. We can analyze the changes in the importance of each city in the national HSR network and then analyze the potential impact of related indicators (such as the centrality) on urban expansion. The transportation of HSR between cities provides spatial connections between cities, that is, urban interaction. It is precisely because of the HSR interaction between cities that all HSR cities in the country form an HSR network. Some cities have strong HSR interactions with other cities, and some cities are relatively weak, and as a result they have various statuses within the HSR network. This factor is a potential impact factor in the case of urban expansion, and it should be taken into consideration in future related studies on the evolution of HSR and urban expansion.

(3) The impact of HSR on refined land use is also a potential direction. As data on multiple types of urban land are difficult to obtain, most of the current research focuses on urban land, but the types are too single. The land use within the city includes education, commerce, residence, leisure, open space, and other types, and even mixed types such as commerce + leisure, education + residence, etc. Some studies in recent years have shown that HSR has a certain influence on the industrial structure of the station area/city and the distribution of advantageous industries. Then, it can be inferred that the spatial distribution and overall area of different types of industrial land are potentially related to HSR, which is a future research direction.

(4) The impact of HSR on urban expansion in this study was quantified based on the area of urban expansion. However, urban expansion may lead to a higher-density urban population, leading to aggravation of the heat island effect. Future research 
can explore the relationship between HSR and the deep-seated results (such as the heat island effect) that are linked to urban expansion.

(5) The resolution of land use remote sensing data is $300 \mathrm{~m}$ in this study. If higher resolution (i.e., $30 \mathrm{~m}$ ) remote sensing data are used, more accurate results may be produced.

(6) The stations may have a more significant effect on urban expansion within a certain buffer zone, and the attenuation effect of geographic distance plays an important role in it. This study only studied the impact of HSR on the overall scale of the city and lacks its micro-study on the evolution of urban land use in different scales of the station buffer zone. In addition, this in-depth study may reflect the multi-scale impact of the HSR transportation hub on the spatial changes (area, expansion direction) of the surrounding urban land. In the era of HSR, the new laws of spatial distribution of land rent in the area near the station area, the new form of industrial structure, and the urban morphology planning around stations, vegetation coverage, and water protection in the station area made by government are different from the overall scale of the city. Therefore, the micro-analysis of urban expansion of the station area, the same way as the European case, is to be carried out further.

(7) The consideration of the regional heterogeneity in this research still needs to be in-depth: this research uses the statistical/survey data of the population of each city to classify when dividing the city sizes. Although the classification is based on official sources in China, with the development of time and drastic economic and social background changes, it has become difficult to accurately classify whether a city is a large or a moderate city with a single population indicator. However, GDP, tourism economy, entity economy, innovation strength, and the number of talents may all be the basis for the classification of cities. In different districts, a more detailed understanding of the changes of it on urban land is of certain significance. Today, HSR lines have covered many cities in the west, such as Lanzhou, Chongqing, Kunming, etc., and many cities have hub stations, which play an important role in communicating multiple lines. Therefore, in the context of the continuous growth and expansion of the HSR network in the west, what changes will happen to the expansion of cities in the west due to its continuous opening? What is the relationship between its expansion and other factors in the city? This study did not analyze the differences between the east, middle and the west, and the study of those is closely related to the revitalization of industries in the west and the high-quality construction of a city.

(8) In addition, this study only uses urban area as a dependent variable for analysis, while the expansion pattern of urban land and other landscape laws has not been analyzed in depth. For example, the compactness of urban land is closely related to the intensive development of urban land, which is important for land resources. It is more important for cities that have a large conflict with population size. In the time of high-speed traffic, how to ensure the growth of the scale of cities and the efficient use of land require further research.

\subsection{Policy Implications}

This study discussed the impact of HSR on urban land expansion in China and subdivided the scales as much as possible to analyze the heterogeneous impact. For example, this study found that the opening of HSR and HSR frequency have different effects on the Beijing-Tianjin-Hebei and Yangtze River Delta urban agglomerations, and HSR frequency only has a negative impact on the expansion of small cities. Therefore, the overall planning of urban agglomerations should grasp the heterogeneous impact of HSR on urban expansion of cities of different sizes and their own urban agglomerations. For example, when the planning departments make the plan of the urban land area for each city in an urban agglomeration, it is necessary for them to fully consider the impact of the new power of HSR, analyze and predict the potential impact of HSR on the growth 
of urban land in cities of different sizes, and continuously adjust planning to achieve coordinated development.

In addition, in the era of HSR, each city should also timely revise its land use planning and the scale of urban land development, including the direction, total amount, and limit of urban land expansion. For a city, the government can add the analysis of multiple time nodes in the planning, construction, and opening of HSR, for example, the time of publication of the HSR line planning documents, the start time of the construction of the HSR line, the time of its completion and opening, and the number of years after its opening and operation, then predict the change trend of the urban land area in their own city based on the situation of urban expansion in nearby cities before and after the opening of HSR. When compiling the new version of the city's master plan, the overall scale of urban construction land should be budgeted according to the different time nodes of HSR.

It is necessary to seize the opportunities brought by the construction and opening of HSR to push urban construction and development and to control the expansion of urban land, to prevent the excessive expansion of urban land from causing waste of construction land and excessive occupation of other kinds of land (such as vegetation cover). In the process of government dynamic monitoring of urban land use, high-resolution remote sensing images should receive more attention. Due to the geographical attenuation law, HSR stations have a significant impact on the surrounding land use. At this time, in order to more accurately calculate and simulate the area, direction, center of gravity, and gradient effects of urban land expansion, high-resolution remote sensing images will provide great help.

In addition to considering the opening of HSR and HSR frequency, this study did not consider other factors about HSR. When the government conducts micro-analysis of urban expansion, it should also consider the impact of the location characteristics of HSR stations on urban expansion, such as the distance to the central area of the county/city. In addition, the successive opening of multiple HSR lines will have different impacts on urban expansion in different time periods.

In addition to the study of a single object of urban land use, the government should also specifically consider the occupation of different types of non-urban land by urban land in the context of HSR in national land and space planning and urban land management. With the continuous improvement and update of remote sensing image classification technology, the classification accuracy of remote sensing images has been improved, and the types of land use have become increasingly diverse. This study has only carried out the conversion of four types of non-urban land to urban land. In fact, the land use structure of various regions varies greatly and the management policies for non-urban land are not completely the same, for example, the proportion of barren land and vegetation cover in the total land use in the northeast and northwest regions is quite different. Therefore, in the context of HSR, each city should combine its own land use characteristics to control the transfer of different types of non-urban land to urban land. For example, in western China, where vegetation cover is abundant, the vegetation cover should continue to be classified in more detail, which will rely on artificial intelligence to improve the efficiency of the remote sensing image interpretation process. Then, hierarchical management of the vegetation cover with better or general ecological environmental benefits will be carried out. Then, the government will prioritize the delineation of vegetation cover areas with weak ecological and environmental benefits and include them in the detailed planning.

Similarly, the government should strengthen monitoring of the conversion of nonurban land to urban land during the different time periods of planning, construction, and operation of HSR lines. For other HSR lines that will be opened in the future, the government can forecast the source scale of urban expansion, that is, the scale of the transformation of various types of non-urban land to urban land and delineate the spatial scope of urban expansion in urban planning in advance. 


\section{Conclusions}

This study used a multi-stage DID model to analyze the impact of HSR on urban expansion in China, including the opening of HSR, HSR frequency, and other socio-economic factors. Taking into account the strong heterogeneity between different regions of China, the discussion was divided into five urban agglomerations and three sizes of city clusters. The conversion of various types of non-urban land to urban land was analyzed for cities in the opening year and the previous year of HSR. Some master conclusions were acquired, as follows:

(1) China's urban land growth rate was relatively fast in the periods of 2010-2013 and 2016-2019, and there was a short period with slower rates of growth from 2013-2016. The growth speed of urban land area in different urban agglomerations (BeijingTianjin-Hebei, the Yangtze River Delta, the Pearl River Delta, Chengdu-Chongqing, and the middle reaches of the Yangtze River) has different characteristics.

(2) Under certain socio-economic conditions, the first opening of HSR has a significant function in promoting urban expansion of Chinese cities. However, several years after opening, HSR no longer plays a role in promoting urban expansion, and the impact diminishes gradually over time. The first opening of HSR has a more significant effect in promoting urban expansion than HSR frequency.

(3) The opening of HSR only has a significant role in promoting urban expansion in Beijing-Tianjin-Hebei, and HSR frequency does not promote urban expansion in this urban agglomeration. The reason for this result may be that there is a vast difference in strength level between the various cities in this urban agglomeration. HSR frequency has a significant influence in promoting urban expansion in the Yangtze River Delta, which is likely related to the small gap in development levels of the cities in this region and the advantages of the coastal location.

(4) The opening of HSR has no significant impact on urban expansion of cities of different sizes. HSR frequency has a significant negative impact on urban expansion of small cities. The reason for this result may be that small cities are affected by the siphoning effect of medium or large cities, resulting in a significant loss of production factors and a lack of motivation for urban expansion.

(5) From a national perspective, the first opening of HSR led to urban expansion that was dominated by the occupation of cultivated land and vegetation cover, of which cultivated land is the main object of occupation in the procedure of urban expansion. After the first opening of HSR, cities in Xinjiang and the Inner Mongolia autonomous region mainly converted barren land and vegetation cover to urban land, and only a small proportion of cultivated land was converted. After the first opening of HSR in Northeast China, urban expansion converted roughly equal areas of vegetation cover and cultivated land, which is related to this region being a main producer of food. The first opening of HSR in cities in southern China results in less conversion of vegetation cover to urban land than in northern China. The reason for the pattern may be that vegetation in the south of China is more important to the ecological environment than in the north of China.

The conclusions of this study have the following practical significance: First, the regional heterogeneity of the opening of HSR and HSR frequency on urban expansion is obtained. In the era of HSR, it provides empirical results for predicting the future growth of urban land. In further research, what should be undertaken is paying full attention to the regional heterogeneity impact of HSR on urban expansion, comprehensively considering the location of the city, scale changes and other location conditions, resource endowments, administrative status, etc., and establishing a comprehensive model. This model will quantitatively predict the potential impact of HSR on the scale of urban land use in different cities and provide a decision-making reference for urban land resource management. Second, this study provides preliminary empirical results for the conversion of non-urban land to urban land influenced by HSR. These conclusions will help city governments to dynamically grasp the different types of non-urban land influenced by 
HSR and facilitate the maintenance of the urban environment and the rational development of natural resources and other refined management. Similarly, in the era of HSR, it is necessary to fully consider the impact of the heterogeneous characteristics of cities on its own conversion of non-urban land to urban land. Combined with the opening of HSR, HSR frequency, and other factors, what can be studied in the future is the quantitative prediction of the impact of the future role of HSR on the scale of conversion of non-urban land to urban land.

Author Contributions: Conceptualization, D.H. and J.Z.; data curation, Z.C. and T.Y.; formal analysis, D.H., J.Z. and L.L.; funding acquisition, D.H. and J.Z.; investigation, D.H. and J.Z.; methodology, D.H. and Z.C.; project administration, D.H. and J.Z.; resources, J.Z.; software, Z.C.; supervision, D.H. and J.Z.; validation, Z.C. and T.Y.; visualization, D.H. and Z.C.; writing一original draft, Z.C. and T.Y.; writing-review and editing, D.H., J.Z. and L.L. All authors have read and agreed to the published version of the manuscript.

Funding: This research was jointly supported by the National Natural Science Foundation of China (41771089), Beijing Social Science Fund (19JDGLA006), the Distinguished Professor Project of Beijing Union University, a grant from the State Key Laboratory of Resources and Environmental Information System, and the Premium Funding Project for Academic Human Resources Development in Beijing Union University (BPHR2017CZ01), the Academic Research Projects of Beijing Union University (ZK40202001, RB202101).

Data Availability Statement: The data presented in this study are available on request from the first author and corresponding author.

Acknowledgments: The authors would like to thank the anonymous reviewers and the editors for their insightful comments and suggestions.

Conflicts of Interest: The authors declare no conflict of interest.

\section{References}

1. Jiao, J.J.; Wang, J.E.; Zhang, F.N.; Jin, F.J.; Liu, W. Roles of accessibility, connectivity and spatial interdependence in realizing the economic impact of high-speed rail: Evidence from China. Transp. Policy 2020, 91, 1-15. [CrossRef]

2. Wang, L.; Acheampong, R.A.; He, S.W. High-speed rail network development effects on the growth and spatial dynamics of knowledge-intensive economy in major cities of China. Cities 2020, 105, 102772. [CrossRef]

3. Zhang, H.; Li, X.; Liu, X.P.; Chen, Y.M.; Ou, J.P.; Niu, N.; Jin, Y.H.; Shi, H. Will the Development of a High-Speed Railway Have Impacts on Land Use Patterns in China? Ann. Am. Assoc. Geogr. 2019, 109, 979-1005. [CrossRef] [PubMed]

4. Wang, J.E.; Jiao, J.J.; Jin, F.J. Spatial effects of high-speed rails on interurban economic linkages in China. Acta Geogr. Sin. 2014, 69, 1833-1846.

5. Shao, S.; Tian, Z.H.; Yang, L.L. High speed rail and urban service industry agglomeration: Evidence from China's Yangtze River Delta region. J. Transp. Geogr. 2017, 64, 174-183. [CrossRef]

6. Wang, D.G.; Niu, Y.; Qian, J. Evolution and optimization of China's urban tourism spatial structure: A high speed rail perspective. Tour. Manag. 2018, 64, 218-232. [CrossRef]

7. Jin, S.H.; Yang, J.; Wang, E.X.; Liu, J. The influence of high-speed rail on ice-snow tourism in northeastern China. Tour. Manag. 2020, 78, 104070. [CrossRef]

8. Meng, X.C.; Lin, S.L.; Zhu, X.C. The resource redistribution effect of highspeed rail stations on the economic growth of neighbouring regions: Evidence from China. Transp. Policy 2018, 68, 178-191. [CrossRef]

9. Guo, Y.; Li, B.; Han, Y.L. Dynamic network coupling between high-speed rail development and urban growth in emerging economies: Evidence from China. Cities 2020, 105, 102845. [CrossRef]

10. Heuermann, D.F.; Schmieder, J.F. The effect of infrastructure on worker mobility: Evidence from high-speed rail expansion in Germany. J. Econ. Geogr. 2019, 19, 335-372. [CrossRef]

11. Hiramatsu, T. Unequal regional impacts of high speed rail on the tourism industry: A simulation analysis of the effects of Kyushu Shinkansen. Transportation 2018, 45, 677-701. [CrossRef]

12. Beckerich, C.; Benoit, S.; Delaplace, M. Are the reasons for companies to locate around central versus peripheral high-speed rail stations different? The cases of Reims central station and Champagne-Ardenne station. Eur. Plan. Stud. 2019, 27, 574-594. [CrossRef]

13. Martin, B.; Ortega, E.; de Isidro, A.; Iglesias-Merchan, C. Improvements in high-speed rail network environmental evaluation and planning: An assessment of accessibility gains and landscape connectivity costs in Spain. Land Use Policy 2021, $103,105301$. [CrossRef] 
14. Shen, Y.; Zhao, J.H.; de Abreu e Silva, J.D.E.; Martinez, L.M. From accessibility improvement to land development: A comparative study on the impacts of Madrid-Seville high-speed rail. Transp. Lett. Int. J. Transp. Res. 2017, 9, 187-201. [CrossRef]

15. China Urban Construction Statistical Yearbook. Available online: http://www.mohurd.gov.cn/xytj/tjzljsxytjgb/jstjnj/index.html (accessed on 10 August 2021).

16. Zhong, Q.Y.; Ma, J.; Zhao, B.; Wang, X.X.; Zong, J.M.; Xiao, X.M. Assessing spatial-temporal dynamics of urban expansion, vegetation greenness and photosynthesis in megacity Shanghai, China during 2000-2016. Remote Sens. Environ. 2019, $233,111374$. [CrossRef]

17. Meng, L.T.; Sun, Y.; Zhao, S.Q. Comparing the spatial and temporal dynamics of urban expansion in Guangzhou and Shenzhen from 1975 to 2015: A case study of pioneer cities in China's rapid urbanization. Land Use Policy 2020, 97, 104753. [CrossRef]

18. Kukkonen, M.O.; Muhammad, M.J.; Käyhkö, N.; Luoto, M. Urban expansion in Zanzibar City, Tanzania: Analyzing quantity, spatial patterns and effects of alternative planning approaches. Land Use Policy 2018, 71, 554-565. [CrossRef]

19. Doe, B.; Amoako, C.; Adamtey, R. Spatial expansion and patterns of land use/land cover changes around Accra, GhanaEmerging insights from Awutu Senya East Municipal Area. Land Use Policy 2022, 112, 105796. [CrossRef]

20. Feng, R.D.; Wang, K.Y. Spatiotemporal effects of administrative division adjustment on urban expansion in China. Land Use Policy 2021, 101, 105143. [CrossRef]

21. Li, G.D.; Sun, S.; Fang, C.L. The varying driving forces of urban expansion in China: Insights from a spatial-temporal analysis. Landsc. Urban Plan. 2018, 174, 63-77. [CrossRef]

22. Xu, T.T.; Gao, J. Directional multi-scale analysis and simulation of urban expansion in Auckland, New Zealand using logistic cellular automata. Comput. Environ. Urban Syst. 2019, 78, 101390. [CrossRef]

23. Costa, A.B.; Zegras, P.C.; Biderman, C. Chasing the city that cannot stop: Exploring transportation and urban co-development in Sao Paulo's history. J. Transp. Land Use 2021, 14, 1075-1098. [CrossRef]

24. Wu, R.; Li, Z.G.; Wang, S.J. The varying driving forces of urban land expansion in China: Insights from a spatial-temporal analysis. Sci. Total Environ. 2020, 766, 142591. [CrossRef]

25. Cao, W.T.; Zhou, Y.Y.; Li, R.; Li, X.C.; Zhang, H.G. Monitoring long-term annual urban expansion (1986-2017) in the largest archipelago of China. Sci. Total Environ. 2021, 776, 146015. [CrossRef]

26. Genel, Ö.A.; Guan, C.H. Assessing urbanization dynamics in Turkey's Marmara region using CORINE data between 2006 and 2018. Remote Sens. 2021, 13, 664. [CrossRef]

27. Jia, S.M.; Zhou, C.Y.; Qin, C.L. No Difference in Effect of High-speed Rail on Regional Economic Growth Based on Match Effect Perspective? Transp. Res. Part A 2017, 106, 144. [CrossRef]

28. Shen, Y.; Silva, J.A.; Martínez, L.M. Assessing High-Speed Rail's impacts on land cover change in large urban areas based on spatial mixed logit methods: A case study of Madrid Atocha railway station from 1990 to 2006. J. Transp. Geogr. 2014, 41, 184-196. [CrossRef]

29. Long, F.J.; Zheng, L.F.; Song, Z.D. High-speed rail and urban expansion: An empirical study using a time series of nighttime light satellite data in China. J. Transp. Geogr. 2018, 72, 106-118. [CrossRef]

30. Li, S.M.; Liu, X.P.; Li, Z.G.; Wu, Z.F.; Yan, Z.J.; Chen, Y.M.; Gao, F. Spatial and temporal dynamics of urban expansion along the Guangzhou-Foshan inter-city rail transit corridor, China. Sustainability 2018, 10, 593. [CrossRef]

31. Tan, R.H.; Zhang, T.Q. Evaluating the impact of high-speed railway on urban land expansion based on multi-period difference-indifference model. China Land Sci. 2019, 33, 39-50.

32. Deng, T.T.; Wang, D.D.; Yang, Y.; Yang, H. Shrinking cities in growing China: Did high speed rail further aggravate urban shrinkage? Cities 2018, 86, 210-219. [CrossRef]

33. Wang, J.T.; Zang, J.X.; Lu, X.C.; Zhao, Y.F. Different effects of urban private transport and public transit on urban sprawl: An empirical test based on the panel data of 65 large and medium-sized cities in China. Econ. Geogr. 2018, 38, 74-81.

34. Wang, S.J.; Wang, J.Y.; Liu, X.P. How do urban spatial structures evolution in the high-speed rail era? Case study of Yangtze River Delta, China. Habitat Int. 2019, 93, 102051. [CrossRef]

35. Wenner, F.; Thierstein, A. High speed rail as urban generator? An analysis of land use change around European stations. Eur. Plan. Stud. 2021. [CrossRef]

36. Wang, S.B.; Guo, J.K.; Luo, X.L.; Liu, J.F.; Gu, Z.N. Spatial Impact of High-speed Railway on the Urban Scale: An Empirical Analysis from Northeast China. Chin. Geogr. Sci. 2020, 30, 366-378. [CrossRef]

37. Zhu, X.H.; Zhong, S.J. Effects of high-speed rail on urban land use from the perspective of "space of flows": An analysis based on DPSIR-PLS model. Resour. Sci. 2019, 41, 2262-2273. [CrossRef]

38. Deng, T.T.; Gan, C.; Peral, A.; Wang, D.D. What caused differential impacts on high-speed railway station area development? Evidence from global nighttime light data. Cities 2020, 97, 12568. [CrossRef]

39. Wang, J.E.; Ding, J.X. High-speed Rail and Its impacts on the Urban Spatial Structure of China. Urban Plan. Int. 2011, 26, 49-54.

40. Garmendia, M.; de Urena, J.M.; Ribalaygua, C.; Leal, J.; Coronado, J.M. Urban Residential Development in Isolated Small Cities That Are Partially Integrated in Metropolitan Areas by High Speed Train. Eur. Urban Reg. Stud. 2008, 15, 249-264. [CrossRef]

41. Zhu, X.H.; Qian, T.N.; Wei, Y.G. Do high-speed railways accelerate urban land expansion in China? A study based on the multi-stage difference-in-differences model. Socio Econ. Plan. Sci. 2020, 71, 100846. [CrossRef]

42. Niu, F.Q.; Xin, Z.L.; Sun, D.Q. Urban land use effects of high-speed railway network in China: A spatial spillover perspective. Land Use Policy 2021, 105, 105417. [CrossRef] 
43. Deng, T.T.; Wang, D.D.; Hu, Y.K.; Liu, S. Did high-speed railway cause urban space expansion? Empirical evidence from China's prefecture-level cities. Res. Transp. Econ. 2020, 80, 100840. [CrossRef]

44. Bel, G.; Holst, M. Evaluation of the impact of bus rapid transit on air pollution in Mexico City. Transp. Policy 2018, 63, 209-220. [CrossRef]

45. Lin, Y.T. Travel costs and urban specialization patterns: Evidence from China's high speed railway system. J. Urban Econ. 2017, 98, 98-123. [CrossRef]

46. Qin, Y. 'No county left behind?' the distributional impact of high-speed rail upgrades in China. J. Econ. Geogr. 2016, 17, 489-520. [CrossRef]

47. China City Statistical Yearbook. Available online: https:/ / data.cnki.net/trade/Yearbook/Single/N2021050059?z=Z006 (accessed on 10 August 2021).

48. Wang, F.; Wei, X.J.; Liu, J.; He, L.Y.; Gao, M.N. Impact of high-speed rail on population mobility and urbanisation: A case study on Yangtze River Delta urban agglomeration, China. Transp. Res. Part A 2019, 127, 99-114. [CrossRef]

49. Fang, L.; Wu, F.P. Can water rights trading scheme promote regional water conservation in China? Evidence from a time-varying DID analysis. Int. J. Environ. Res. Public Health 2020, 17, 6679. [CrossRef]

50. Climate Change Initiative Land Cover. Available online: http:/ / maps.elie.ucl.ac.be/CCI/viewer/ (accessed on 10 June 2021).

51. Data Introduction. Available online: http://maps.elie.ucl.ac.be/CCI/viewer/download/ESACCI-LC-Ph2-PUGv2_2.0.pdf (accessed on 5 June 2021)

52. Shengming Timetable. Available online: http://www.smskb.com/ (accessed on 10 August 2021).

53. Jipin Timetable. Available online: http://www.uzzf.com/Soft/19356.html (accessed on 10 August 2021).

54. Zhinanzhen Timetable. Available online: https://www.jb51.net/softs/38049.html\#downintro2 (accessed on 10 August 2021).

55. City Size Division. Available online: http://www.gov.cn/zhengce/content/2014-11/20/content_9225.htm (accessed on 10 August 2021). 